\title{
Potential fabric-reinforced composites: a comprehensive review
}

\author{
K. M. Faridul Hasan ${ }^{1, *}$ (D), Péter György Horváth ${ }^{1}$, and Tibor Alpár ${ }^{1, *}$ \\ ${ }^{1}$ Simonyi Károly Faculty of Engineering, University of Sopron, Sopron 9400, Hungary
}

Received: 9 March 2021

Accepted: 12 May 2021

Published online:

26 May 2021

(C) The Author(s) 2021

\begin{abstract}
Fabric-based laminated composites are used considerably for multifaceted applications in the automotive, transportation, defense, and structural construction sectors. The fabrics used for composite materials production possess some outstanding features including being lighter weight, higher strength, and lower cost, which helps explain the rising interest in these fabrics among researchers. However, the fabrics used for laminations are of different types such as knit, woven, and nonwoven. Compared to knitted and nonwoven fabrics, woven fabrics are widely used reinforcement materials. Composites made from fabric depend on different properties such as fiber types, origin, compositions, and polymeric matrixes. Finite element analysis is also further facilitating the efficient prediction of final composite properties. As the fabric materials are widely available throughout the world, the production of laminated composites from different fabric is also feasible and cost-effective. This review discusses the fabrication, thermo-mechanical, and morphological performances of different woven, knit, and nonwoven fabric-based composites.
\end{abstract}

Abbreviations

2D Two-dimensional

3D Three-dimensional

UV Ultraviolet

GSM $\quad \mathrm{G} / \mathrm{m}^{2}$

FEA Finite element analysis

CDM Continuum damage mechanics

WFC Woven fabric-reinforced composites

AgNP Silver nanoparticle

MDI Methylene diphenyl diisocyanate

$\begin{array}{ll}\text { MUF } & \text { Melamine-urea-formaldehyde } \\ \text { PP } & \text { Polypropylene } \\ \text { NRC } & \text { Nonwoven reinforced composite } \\ \text { KFRC } & \text { Knitted fabric-reinforced composites } \\ \text { PLA } & \text { Polylactic acid } \\ \text { PHBV } & \begin{array}{l}\text { Poly(3-hudroxybutyrateco-3- } \\ \text { hydroxyvalerate) }\end{array} \\ \text { PE } & \text { Polyethylene } \\ \text { PVC } & \text { Poly(vinyl chloride) } \\ \text { PS } & \text { Polystyrene }\end{array}$

Handling Editor: Stephen Eichhorn.

Address correspondence to E-mail: k.m.faridul.hasan@phd.uni-sopron.hu; alpar.tibor@uni-sopron.hu 


$\begin{array}{ll}\text { MOR } & \text { Modulus of rupture } \\ \text { MOE } & \text { Modulus of elasticity } \\ \text { TGA } & \text { Thermogravimetric analysis } \\ \text { DTG } & \text { Derivative thermogravimetric } \\ \text { DSC } & \text { Differential scanning calorimetry } \\ \text { R\&D } & \text { Research and development } \\ \text { PBS } & \text { Poly(butylene) succinate } \\ \text { SWOT } & \begin{array}{l}\text { Strengths, weaknesses, opportunities, and } \\ \text { threats }\end{array}\end{array}$

\section{Introduction}

Composite materials acquire increased mechanical strength in the reinforcing phase. The ultimate composite products are stronger, stiffer, and harder than the matrix. Recently, fabrics have received increasing attention when compared to other reinforcement materials like particles, fibers, and so on. Although the fibers are applied for three-dimensional (3D) or two-dimensional (2D) structures [1, 2], the architectures are also used through textile fabric (such as woven, nonwoven, knitted, and braided) [3-9]. In 3D fabrics, the fibers are intermeshed lengthwise, thickness-wise, and crosswise, while 2D woven fabrics are made of two sets of yarn (one is lengthwise $0^{\circ}$ and the other is crosswise in a $90^{\circ}$ direction) through conventional weaving technology. Nevertheless, the low fatigue and stiffness resistance characteristics of $2 \mathrm{D}$ fabric when applied to shear stress make them a challenge to use. In addition, composites made of 2D structures are weaker and tensed to delaminations. However, 3D fabrics enhance the thermal stability and mechanical performances in the composites as well as reduce the delamination for the fibers present in perpendicular directions. The design of the fabrics could be tuned during the manufacturing stages to increase the ultimate performances from the final composite products according to the requirements.

Textile fabrics possess notable potentiality for composites used in automobiles, construction, furniture, and buildings. Both natural and synthetic fiberbased fabrics are used in composite production. Natural fibers include hemp, ramie, flax, jute, sisal, cotton, agave, and so on [10-13], whereas synthetic fibers are carbon, glass, nylon, polyester, ultra-high molecular weight polyethylene, and so on [14-20]. However, composites made from natural fiber-based fabrics are becoming increasing popular due to their environmental sustainability. Conversely, synthetic fabric-based composites are also used extensively for their low cost and ease of production. Most aerospace, marine, and automotive companies currently use synthetic fiber-based composites [21, 22]. Fiber properties, fabric structure, the number of fabric layers, and areal density all play significant roles in composite performance. Furthermore, together with enhanced mechanical properties, different polymeric material/nanoparticle loading also plays a notable role in providing composite materials with different functionalities like antibacterial properties and UV-resistance. Generally, different thermoplastic, thermosetting, and cementitious materials are used for developing laminated fabric-based composite panels [23-27]. The use of polymeric matrix in laminated composite depends on the necessities as some polymers are suitable for better mechanical properties generation, while others are better for water absorbency and thermal conductivity. The classifications of different fabrics and the associated structures used as the reinforcement of composite materials are shown in Figs. 1 and 2, respectively.

Fabrics possess excellent drapability around any device or tool; this can be further facilitated with a suitable tool shape and fabric surface [30]. Various processing methods, such as compression forming, roll forming, diaphragm forming, molding, and machining, are applied for the formation of fabric-reinforced composites. Previously, researchers were involved with unidirectional fabric composites developments [31-33]. However, following this, researchers began to investigate discontinuous unidirectional fabric composites [34, 35]. Woven fabrics were considered as potential composite material, but the usage of knitted fabrics also became popular in later periods. However, polymeric material used with the fabric reinforcement indicates numerous potentialities for high-performance composite materials. Researchers are currently examining numerical simulation software to predict material properties, which could facilitate the adequate corrective actions prior to production. This review provides an overview of various woven, nonwoven, and knitted fabric-based composites, polymeric matrices, reinforcement methods, numerical modeling, application areas, and marketing aspects. This work can help facilitate future researchers and industrialists with broad information 


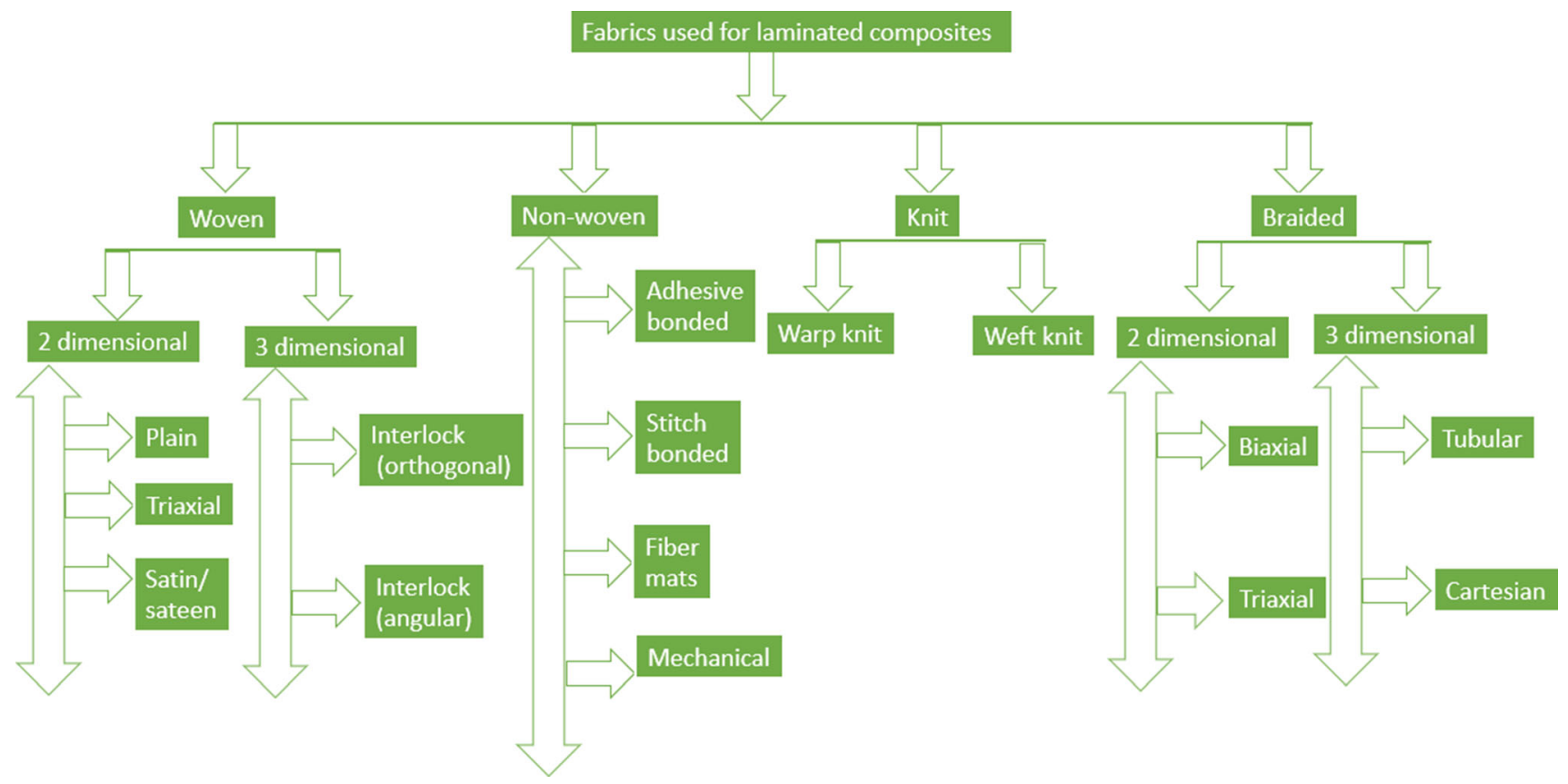

Figure 1 Structural classification of fabrics used for laminated composites production.

Figure 2 Textile fabrics structure: 2D woven fabric (ac), 3D woven fabric $(\mathbf{d})$, braided woven structured fabric (e and $\mathbf{f}$ ), knitted fabric ( $g$ and $\mathbf{h}$ ), and warp knitted fabric. Adapted with permission from Elsevier [28, 29]. Copyright Elsevier, 2005 and 2016.

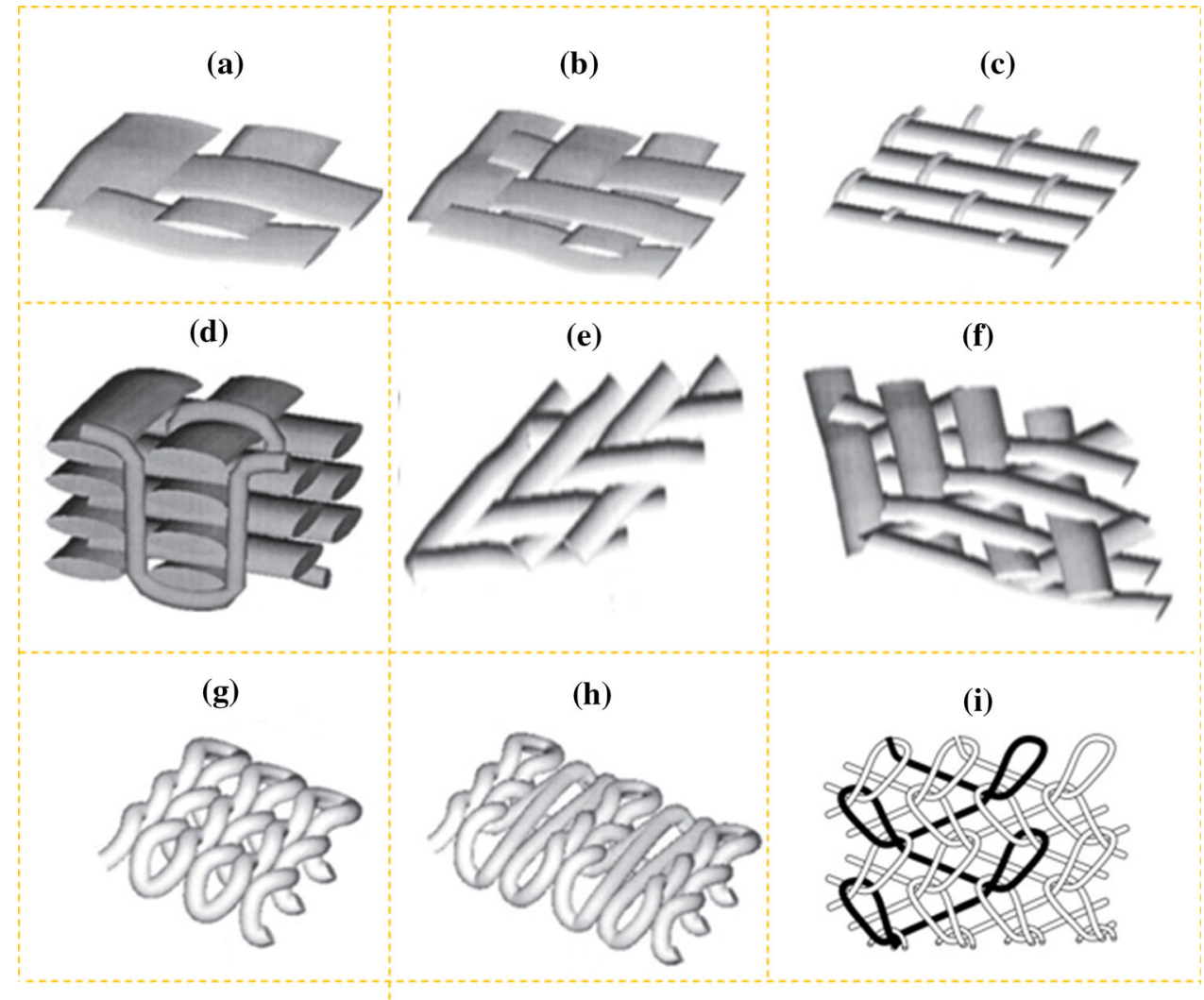


regarding new and potential routes for laminated composite production.

\section{Fabrics used for composites}

Textile-reinforced composite materials are not only cheaper and more widely available, they are also increasingly being produced via automated rather than manual methods. In this regard, textile fabrics (Fig. 3), which is pre-formed in terms of weaving, knitting, braiding, stitching, nonwoven, and so on, are being increasingly considered. However, the structure of selected fabrics for reinforcement plays a significant role for achieving the expected performance characteristics from composites. Fabrics with higher twist provide higher strengths than those with lower twists due to efficient distributions of stress [36]. Zhou et al. [20] have conducted an experiment where they studied different structures of carbonbased woven fabrics in terms of plain and twill structure and found that differences in fabric structure at uniaxial directions exert limited influences on the strength and modulus of the composites. The same study further claimed that particular fabric structure also exerts influences on the stress concentrations and crack propagations [20]. In another study, Aghaei et al. [37] mentioned that fabric geometry (woven) plays a vital role in influencing the mechanical performances of the composites. Researchers are also becoming increasingly interested in knitted fabric as another prominent potential reinforcement material for composite development. Chen et al. developed sandwich composite panels with higher tensile strengths $(124.28 \pm 18.64 \mathrm{MPa}$ for carbon fabric/epoxy/glass knit fabric and $332.36 \pm 53.18 \mathrm{MPa}$ for carbon fabric/epoxy/carbon knit fabric) and compressive performances by using weft knitted structured fabrics [38]. Ramakrishna conducted research on wale (lengthwise yarn) and course (crosswise yarns) directions of knitted fabric reinforced with epoxy composites tested in terms of tensile strengths and elastic modulus where the elastic modulus was predicted as per laminated plate theory and cross-over modeling [39]. The same study reported that tensile property is strongly dependent on the fiber content in composite systems whereas the strengths grew by the increased fiber contents [39]. Furthermore, knitted fabric-reinforced composites exhibit higher tensile strengths in wale directions compared to the course direction of fabric [39]. Fiber content could be increased via the following parameters:

(a) through increasing the linear density of the yarns,

(b) through increasing the stitch density or loop of the fabrics, and

(c) through increasing the number of plies in the yarns.

Furthermore, preforms (Fig. 4) of fabric-based composites are also important in the design and fabrication. In this regard, Quan et al. [40] modeled multi-directional preforms according to fused filament fabrication methods [41]. Tejyan et al. conducted research on nonwoven fabric of 400 and 600 GSM $\left(\mathrm{g} / \mathrm{m}^{2}\right)$ with resin through implementing a hand-layup technique. The researchers found significant flexural strengths, impact energy, and thermal conductivity [42]. They summarized that composites thermal conductivity decreases as mechanical strengths and associated fabric density increases [42]. Polyethylene terephthalate (80\%) and Kevlar (20\%) were blended together to form nonwoven fabric and later, as-produced fabrics (two pieces) were interlayered with the needle-punching method by
Figure 3 Typical fabric structures used for composites: a woven, $\mathbf{b}$ knitted, and c nonwoven. Adapted with permission from Elsevier [44]. Copyright Elsevier, 2016.

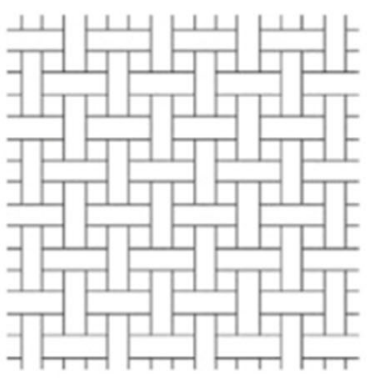

(a)

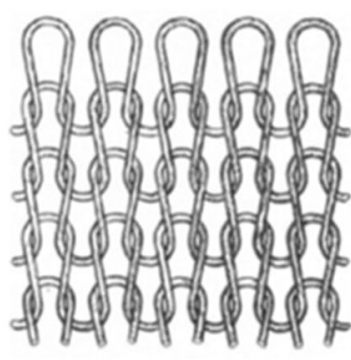

(b)

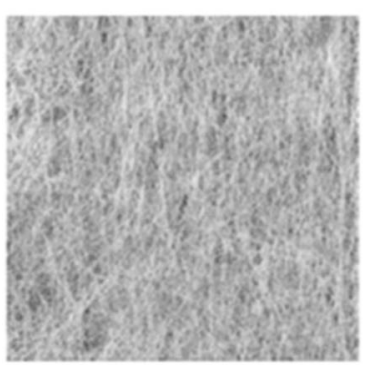

(c) 
(a)

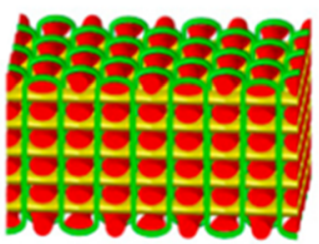

(b)

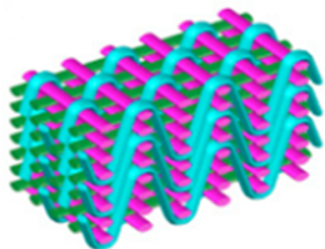

(c)

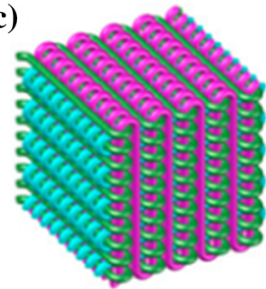

(d)
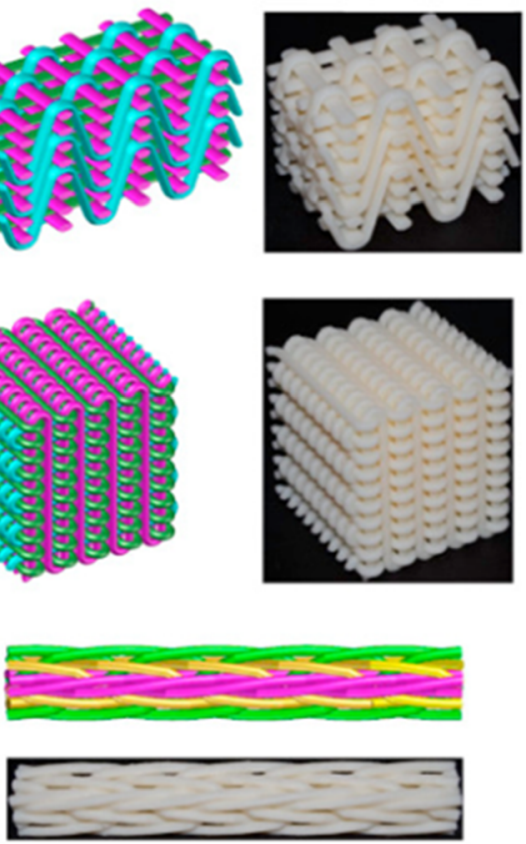

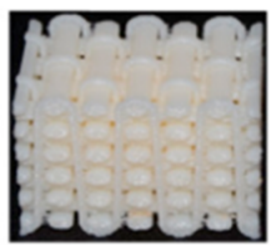

(e)

(g)

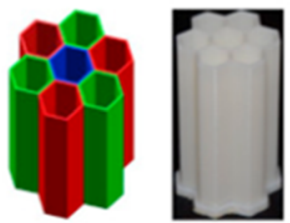

(h)

(f)
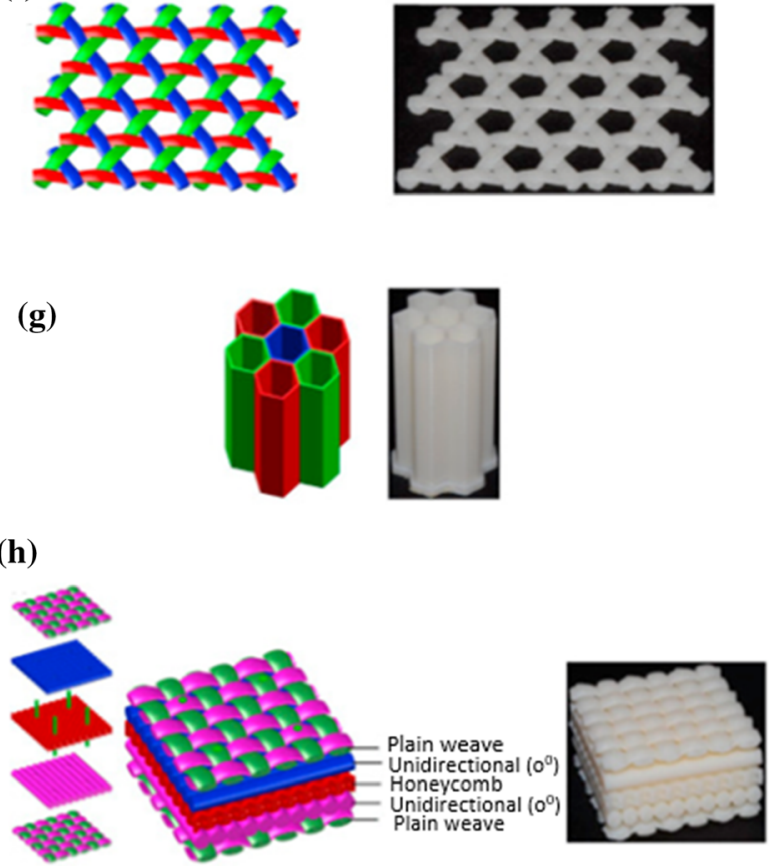

c Orthogonal woven (3-D), d 4-step braided (3-D rectangular), e plain woven (2-D), $\mathbf{f}$ woven (2-D triaxial), $\mathbf{g}$ honeycomb (hexagonal cells), h multilayered sandwich (Z-pinned). Adapted with permission from Elsevier [40]. Copyright Elsevier, 2015.

\section{Plain woven fabrics}

The simplest woven fabric structure is where the weft/filling yarns are alternately passed through over and under a warp yarn (Fig. 5). Similarly, every warp yarn is also passed through over and under the filling yarns. Plain weave fabrics are considered structurally symmetrical, having good porosity and stability. On the other hand, despite advantageous features of plain weave structured fabrics, some disadvantages like higher creep level are generated due to the excessive drapability of this structure, which negatively influences the mechanical properties of the composites [45]. Taffeta, crepe, muslin, and organdy are some of the commonly used examples of plain weave structured fabrics. Furthermore, plain weave fabrics are also classified into a further two categories: (a) warp rib weave and (b) weft rib weave. 
Figure 5 Different derivatives of woven fabrics: a plain weave, $\mathbf{b}$ six weft satin effects, and c six weft twill effects. Adapted with permission from Elsevier [46]. Copyright Elsevier, 2020. (a)
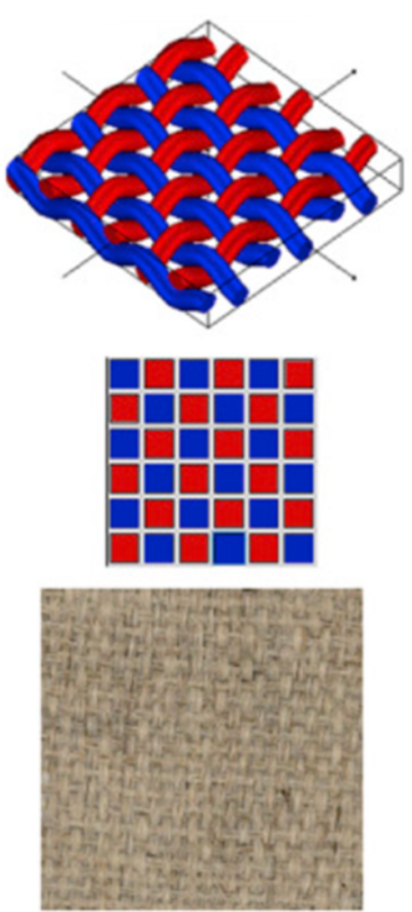

(b)
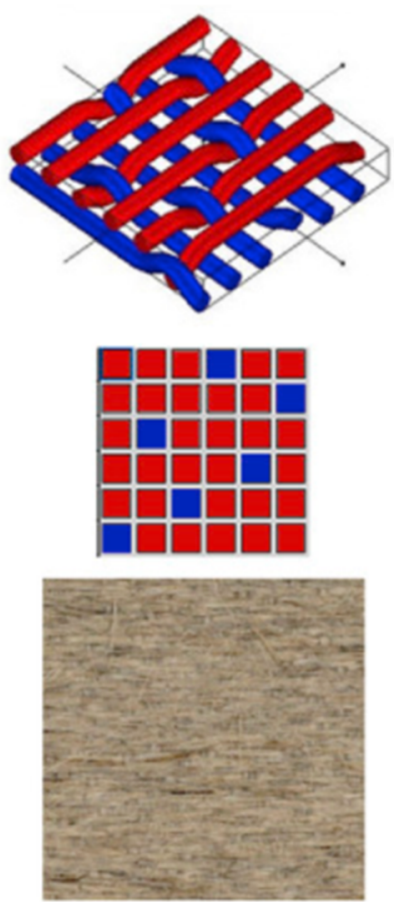

(c)
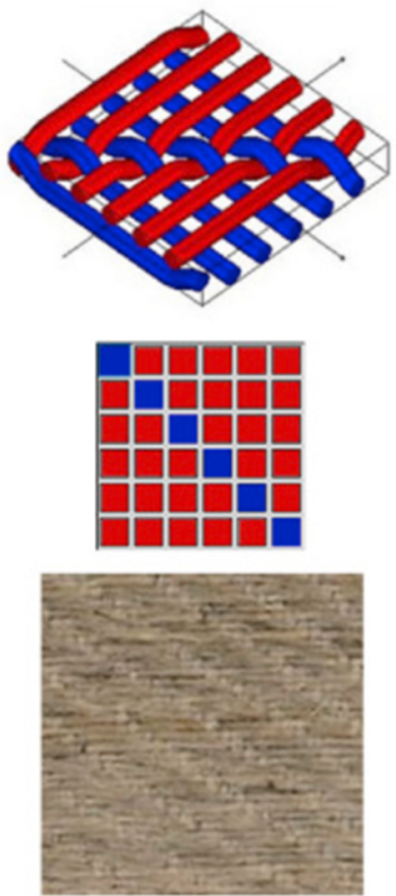

The warp rib weaves are performed through the insertion of picks (two or more) in the same shed, which is why it is also termed a warp-faced structured fabric. Furthermore, the cover factor and crimps are higher for warp than they are for weft. Conversely, with weft rib fabrics, the ends (two or more) are woven together as one structure. In this case, however, the cover factor could have an increased possibility of having a higher cover factor as two ends are woven into one. Nevertheless, weft rib woven structured fabrics are more expensive than warp rib woven structured fabrics, which explains why they are not commonly used.

\section{Twill woven fabrics}

Warp yarns (one or more) are woven under and over weft yarns (two or more) in a regular pattern to form twill woven fabrics (Fig. 5). However, a straight/ broken diagonal appearance of rib structure is found for this type of fabric. Compared to rib fabrics, a superior drapability and wet out property is observed in twill fabrics; however, a slight decline in stability is observed. Nonetheless, if the fabric is mechanized and produced to ensure minimized creeps, it is possible to obtain a positive attribution toward higher mechanical performances.
Figure 6(a) contains physical photographs of twill flax woven fabric.

\section{Zigzag weave}

A zigzag effect on woven fabric is created if the diagonal directions in a twill fabric are reversed across the width periodically. With this special weave, two different $S$ and $Z$ twill effects are used with equal repeats.

\section{Diamond twill}

Two zigzag weaves having equal repeats (symmetrical) are combined to produce diamond effects on woven fabrics. The fabrics are symmetrical across vertical and horizontal directions in diamond twill.

\section{Herringbone weave}

The line of twill is commenced in a usual pattern in the case of herringbone twill; however, the direction of twill is also reversed periodically as it is in zigzag patterns of weave, but the interlacement order is also reversed at the reversal points. 

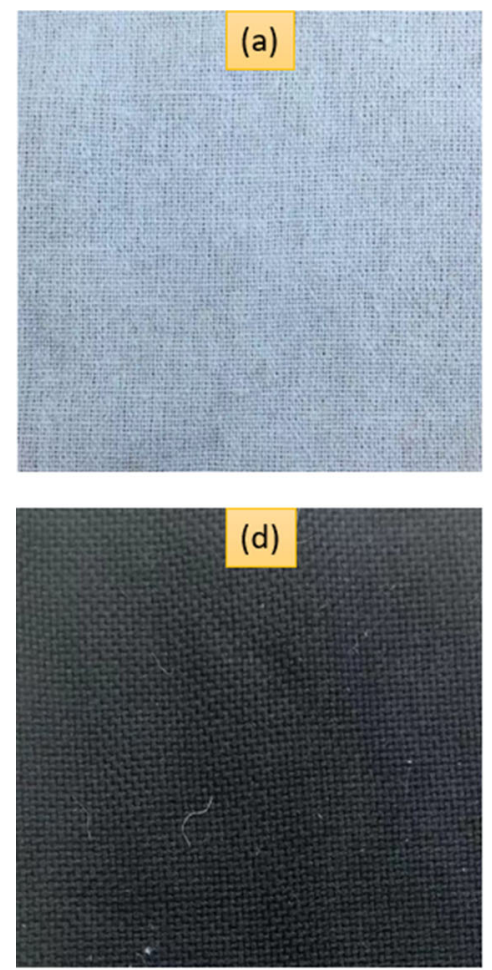
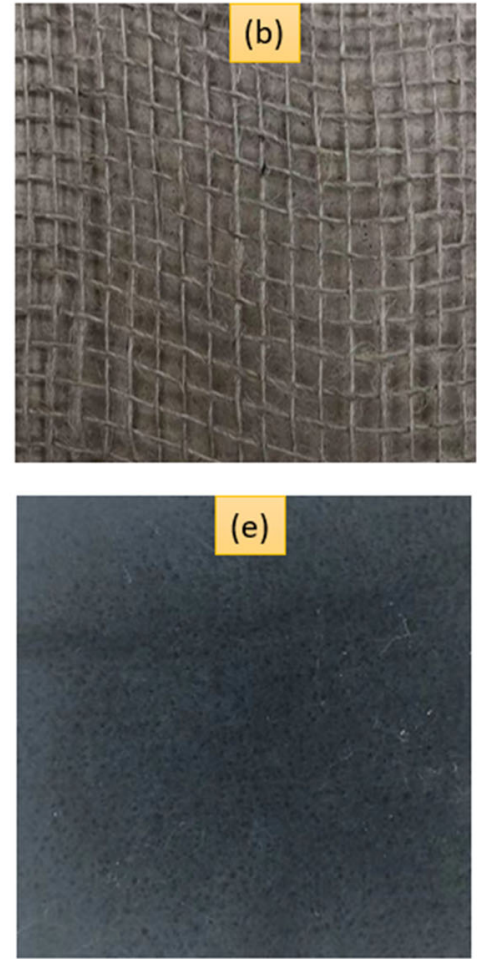
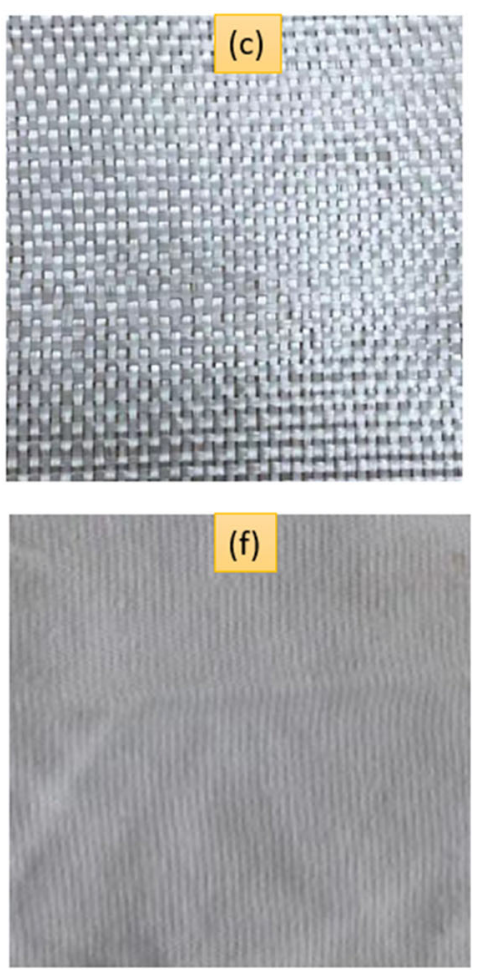

Figure 6 Different fabrics (physical photograph) used for composites production: a flax woven fabric, $\mathbf{b}$ jute woven fabric, $\mathbf{c}$ glass woven fabric, $\mathbf{d}$ carbon woven fabric, e carbon nonwoven fabric, and $\mathbf{f}$ cotton knit fabric.

\section{Diaper weave}

Two herringbone designs are combined together to produce diaper woven fabrics. However, this design is symmetrical to the diagonal lines.

\section{Sateen/Satin weave}

The high luster effects on the one side of the fabric are produced through the use of the floating yarns via weaving operations. With the satin/sateen weaving processing, low twisted warp yarns float through filling yarns (four or more) (Fig. 5). These kinds of fabric are flat and have higher drapability and wet capability. Furthermore, it is possible to achieve improved mechanical performances to generate lower crimps. Moreover, the typical weaving pattern for satin/sateen weaves the yarn in the closest proximity, which results in tightly woven fabrics.

\section{Leno weave}

The stability of open fabrics could be enhanced by using a lower yarn count for this style. Leno weave fabrics are used in conjunction (generally) with different weave design styles. Otherwise, leno weave fabrics could not be efficiently used as a composite material due to their openness.

\section{Knitted fabrics}

Knitted fabrics are also termed as porous and elastic fabric materials, which are produced in terms of yarns interlocking through the use of needles. Knitted fabrics are cheaper and are employed in a higher volume of production than woven fabrics. Knitted fabrics (Fig. 6f) are made of loops (Fig. 7); the vertical loops are called wales and horizontal loops are called course. However, knitted fabrics are more elastic and lighter. Generally, knitted fabrics are of two types: (a) weft knitted fabrics and (b) warp knitted fabrics. However, weft knitted fabrics exist in many derivatives including single knit, double knit, and specialized knit. Single knit fabrics are classified as single jersey and lacoste, which are widely manufactured by the production houses. Conversely, double knit derivatives are entailing rib, purl, interlock, cardigan, bird's eye, Pointelle, and Milano ribs. Terry, fleece, French terry, velour, silver knit, and jacquard jerseys are some examples of specialized knitted fabrics. On 


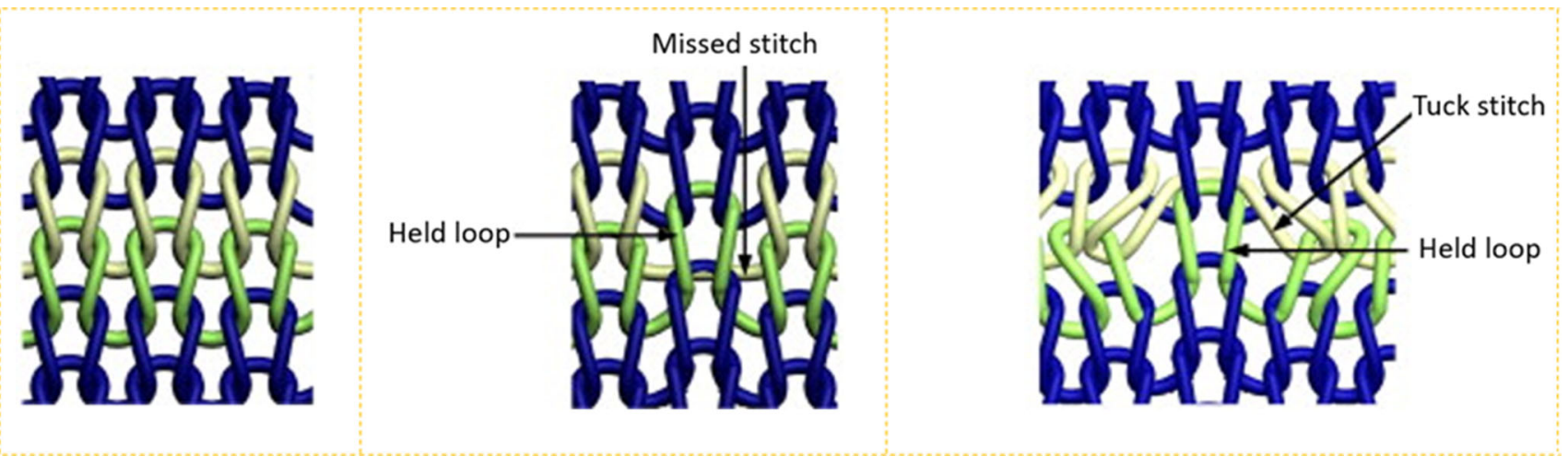

Figure 7 Different types of loops used for knit fabrics production: a knit, $\mathbf{b}$ tuck, and $\mathbf{c}$ miss stitches. Adapted with the permissions from Elsevier [50]. Copyright, Elsevier 2009.

the other hand, tricot and Rachel are two other wellknown warp knitted fabrics. The above discussions are collected according to "Textile School" [47]. Cuong et al. conducted a research on aramid and glass fiber-reinforced composites to investigate the cooling effects on PP-reinforced composite and found that flexural properties are influenced by cold conditioning [48]. Furthermore, the gradual cooling of samples also displays higher crystallinity. The same study also reported interesting findings such as higher flexural strength in the wale directions compared to course directions of the fabrics [48]. Qi et al. conducted another research study on weft knitted fabric composites in biaxial directions and found superior tensile performances [49].

\section{Nonwoven fabrics}

Generally, nonwoven fabrics are considered advanced materials produced from short and long fibers (chopped/irregular fibers) that are bonded through mechanical and chemical processes or through the application of different solvents [51]. The bonding reagents used are spraying, coating, printing, or saturation techniques for chemical bonding to produce nonwoven fabrics to keep the fibers together. Stiffness and water repellency properties are also executed for this kind of chemical agents in terms of functional finishing. Furthermore, bonding reagents could also be facilitated further to improve enhanced flammability, surface roughness, and visual appearance [51]. However, according to manufacturing techniques, nonwoven fabrics are divided into several classifications like spun-bonded, heat sealing, spunlace, needle punched, hydrophilic, melt- blown, stitch-bonded, airlaid pulp, and wet nonwoven fabrics [52]. The recycled fibers could be utilized for nonwoven fabric preparations. However, nonwoven fabrics are water permeable and are weaker when wet. Moreover, nonwoven fabrics are comparatively cheaper. Nevertheless, it is interesting that nonwoven fabrics could be used for multifaceted applications and in application areas ranging from civil and mechanical engineering [51] to clothing. Comparatively, nonwoven fabrics are much cheaper than other types of fabrics. Shi et al. developed composites from nonwoven cotton fabric reinforced with polydimethylsiloxane through microwave absorption for fabrications and found high-performance electromagnetic wave absorbance characteristics [53]. Wang et al. developed a laminated composite from carbon black incorporated with nonwoven fabric reinforcements with polypropylene and found a significant toughening property [54]. A report by Kakati et al. mentioned that the developed composites from a blend of unsaturated polyester matrix reinforced with nonwoven jute was found to have improved thermo-mechanical and water resistance performance. A physical and morphological representation of needle punched nonwoven fabric is shown in Fig. 8.

\section{Factors affecting the fibers, yarns, and fabric structure in composites}

The straight geometry of yarns in the fabric structure is extremely significant in order to achieve the efficient reinforcement effects in polymeric composites. The factors are discussed below: 
Figure 8 Nonwoven fabrics (need-punched): a physical picture and $\mathbf{b}$ morphological photograph. Republished with permission from Elsevier [55]. Copyright Elsevier, 2020.

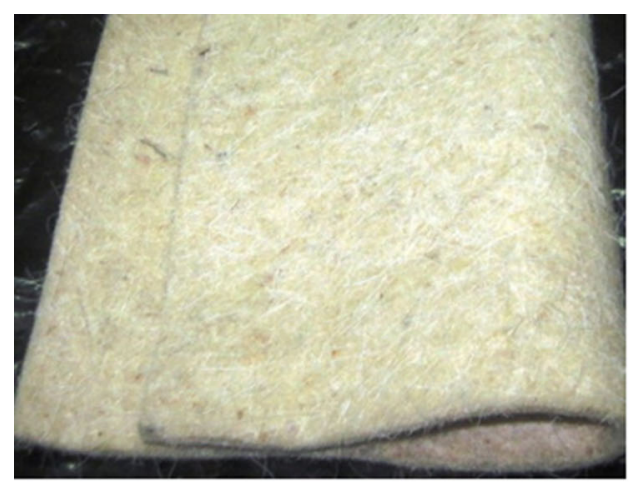

(a)

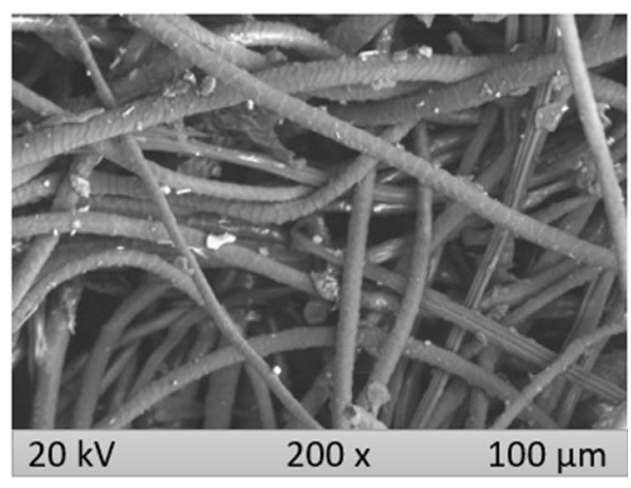

(b)

\section{Influence of fracture}

Impact property is extremely important as the structural laminated composites are not always flat, but occasionally curve in one, two, or even more directions. However, studies on impact properties are still limited. If this property is not considered thoroughly during the composite development, it could, consequently, cause destruction and could lead to accidents when applied to marine-based applications or other relevant cases [56]. It is challenging to design and develop models to understand the factors and phenomena associated with impact damage and related resistance characteristics. Johnson et al. [57] discussed FEA (finite element analysis) and composite modeling that could demonstrate the frameworks within in-ply as well as delamination failure against impact load. They [57] proposed a CDM (continuum damage mechanics) model for laminated composites from fabric. However, several parameters influence impact damage on laminated composites [58]; these are listed below:

- Laminate stacking sequence

- Laminate geometry

- Properties and nature of associated matrix and reinforcements

- Composite mass and velocity

\section{Influences of stitching and layout}

Fabric reinforcement, different stacking sequences, composite dimensions (2D/3D), and other factors significantly influence the mechanical properties of composites. The delamination shape of interface in the composite system could be determined through the geometry of fractured areas and the sequence of stackings near the interface. However, the mechanism of intraply cracking is triggered by shear stress (transverse). Moreover, major energy is dissipated by the dominant fracture processes of crack propagations in the laminates. However, the properties of associated fiber are responsible for the anticipated damage in the composite matrix systems. Ahmad et al. [55] conducted research on fabricating hemp/ polyethylene terephthalate interwoven laminated composites by using vacuum infusion methods reinforced with epoxy resin and found satisfactory thermo-mechanical performances.

\section{Influence of material characteristics}

The characteristics of laminated fabric and associated fibers along with their interface and matrix play a significant role in determining the ultimate performance of the laminated composites. Costa et al. reported that void content and associated size are dependent on the resin applied to the laminated composites [59]. The same study also found that epoxy/carbon-laminated composites produce more void than bismaleimide/carbon [59]. The reason for this difference in characteristics may be the use of bio-based bismaleimide, which influenced the creation of fewer voids. In another study, Corbin et al. [60] noted that even the structure (like weaving pattern) of reinforced fabrics could influence the mechanical performances of the composites. Furthermore, the incorporation of different natural and synthetic fiber-based fabrics together with polymeric resin could also influence the improved mechanical properties more than the individual reinforcements [61]. 


\section{Influence of preload}

Research to understand the preload of composites in terms of tensile stresses against crack resistance has also been conducted. Schoeppner et al. [62] reported that the time required for stiffening effects started to decline on pre-tension for reaching the maximum load with the increased indentation depth. The effects of tensile preload were studied by Langella et al. [58] for thinner woven fabric laminated composites for helicopter blades. The researchers monitored the final fractured shape and load versus the associated displacement curve for tensile loads. They noticed that the size of impact fracture/damage grows with the increase of tensile loads, perpendicularly to the tractions [58].

\section{Influence of environmental condition}

Generally, structural composites are subjected to various environmental conditions; hence, they can absorb moisture/solvent/oil from the surrounding atmosphere, which influences the thermal, electrical, mechanical, and physical properties significantly [62]. The strength and stiffness of composite materials are influenced by moisture absorption with temperature changes. However, very few studies have been conducted to investigate this phenomenon. Sateesh et al. [63] performed another investigation to identify the impacts of moisture on the mechanical properties of E-glass/polyester polymeric resin composite by exposing it to water for 6-month durations. The results indicated a significant decline in flexural modulus. The reason for that is the loss in bonding strengths between the fiber and polyester resin in the environmental conditions. However, hydrophobic film could be used to create a thinner film barrier of polyvinyl fluoride, polytetrafluoroethylene, polyimide, polyether ether ketone on the composite surfaces [62]. However, the following factors could influence the effects of moisture:

- Matrix characteristics

- Properties of reinforcement fabrics in laminates

- Degree of curing the polymers in composite systems

- Polarity, porosity, and homogeneity of constituent fiber materials in the laminates
- Exposed environmental conditions (relative humidity, temperature, and pressures) of laminates

- Surface hydrophobicity

- Dimensional characteristics of composites (like thickness, density, etc.) and the architectural design of final products.

\section{Influence of crack propagations}

The degree of delamination during the application of tensile and bending force to estimate the residual characteristics of laminated composites also needs to be understood. However, a detailed prediction regarding fracture could not be precisely defined as delamination is mainly responsible for decreased mechanical performances; displacement sizes could be predicted. Hirshikesh et al. [64] conducted a study to uncover the routes for crack propagations and the influence of fiber to matrix interactions on these cracked routes. This study summarized that fiber orientations and composite load-bearing capacity influence fracture patterns. Nonetheless, this phenomenon is not workable in similar patterns when fiber interspacing is higher [64]. Researchers and manufacturers frequently choose woven fabrics for their higher fracture toughness and better transverse properties [65]. This study further claimed that the damage of fiber/matrix delaminations in glass/carbon woven fabric occurs due to the adhesive layer at interface [65]. Consequently, higher energy is required to pull out fibers.

\section{Influence of residual properties}

Damage tolerance and associated corrective actions to prevent it requires the determination of developed fractures phenomenon/state on the laminate. This term demonstrates the behavior of composite structures against applied force and associated damage to predict residual properties. Zhang et al. [66] conducted a study on fiber-reinforced laminated composites and polymeric composites and investigated micromechanical characteristics via higher temperature curing methods. The study further reported that the residual stresses start to decline with time. After a duration of $34 \mathrm{~h}$, stresses showed a smaller asymptotic value [66]. Furthermore, remaining residual strains could still influence the damage evolution in 
cross-ply laminates against subsequent tensile loads [66]. Different techniques to determine residual stresses like destructive, non-destructive, and slitting methods are available [67]. Nonetheless, with destructive and non-destructive methods, the strains are assessed from the attribute residual stresses. Tabatabaeian et al. conducted an experiment on polymeric composites from multiple glass-reinforced composites [68]. Their responses were investigated in terms of mechanical performance and residual stresses [68]. However, they [68] determined residual stresses through the application of slitting methods [69]. The results revealed that variation of fiber directions in the laminates significantly changes stress response [68]. Furthermore, residual stresses of the composites also showed a decreasing trend with the exposure of thermal fatigue [68].

\section{Composites from fabrics}

Woven, nonwoven, and knitted fabrics are widely used to produce composite materials. The composites from different fabrics are discussed below:

\section{Composites from woven fabric}

Woven fabric-reinforced composites (WFCs) are made of stacked fabric and polymers in the composite system. WFCs are advantageous for their higher strength, stiffness, satisfying energy absorption, and superior fatigue behavior. Woven fabrics are constructed with two sets of yarns or tows through interlacing (warp-lengthwise directions and weft-crosswise directions) by weaving operations in loom. Woven fabrics are classified as plain, herringbone, satin/sateen, twill, diamond, and zigzag-based on the different yarn patterns. The higher packing density of yarn in terms of fabric thickness is a competitive advantage of using woven fabrics compared to the braided and knitted structures. However, the yarns are crimped across the lengthwise directions in woven fabric, which results in composites with reduced stiffness and tensile strengths in the case of unidirectional laminates [70]. However, with the advancement of textile technologies, WFCs are gaining popularity. The usage of thermoplastic resins with the fabric reinforcements induces fast and automated production by ensuring higher mechanical performances. Nevertheless, laminated composites formed from a different number of layers of woven fabrics are susceptible to cracking problems with various failure modes in composite surface interface. Delamination is another major challenge that significantly affects the stiffness and strength of the woven fabric-reinforced composites structure. Delamination may occur when applying the load by means of compression, tension, bending, pressure, and different levels of energy during composite formation, which may affect the polymeric structure. Consequently, researchers are focused on resolving this challenge [71]. The samples of different fiberbased WFCs developed in our laboratory are shown in Fig. 9.

Fiber crimp is another critical challenge for laminated composites efficiency. Fiber crimp causes local stress on composites-hence, the matrix may crack due to the debonding in the fiber interface. Consequently, numerous studies were conducted to discover the causes of delamination in woven fabricreinforced composites [72-74]. The mechanical properties of WFCs are influenced by the surface treatments of the biofibers. The unidirectional tapes of woven fabrics have facilitated WFCs by increased fracture toughness. The main challenges and benefits of WFCs manufacturing could be divided into two broad categories: (a) improving the material properties of composites, (b) modifying the fiber structure/ architecture [71, 75]. There are also tools such as PDM (progressive damage modeling) for predicting the stress distribution in the matrix along with the possible damage/failure mechanism both for 2D and 3D WFCs [76, 77]. According to the model, damage occurs due to the dissipation of fracture energy at the time of failure; the amount is determined by the displacement in each failure mode. Different studies also tried to investigate the fatigue damage of plain WFCs by using the PDM model [78].

Some studies have reported on fabrics from similar fibers, but with variable matrices (thermoset/thermoplastics) or different fabrics with same matrices to manufacture laminated composites. Impact strength is associated with a tough matrix, as reported for carbon-based WFCs with thermoplastic and thermoset polymers [79].

\section{Composites from nonwoven fabric}

The fibers or filaments are entangled together by thermal, chemical, or mechanical bonding through 


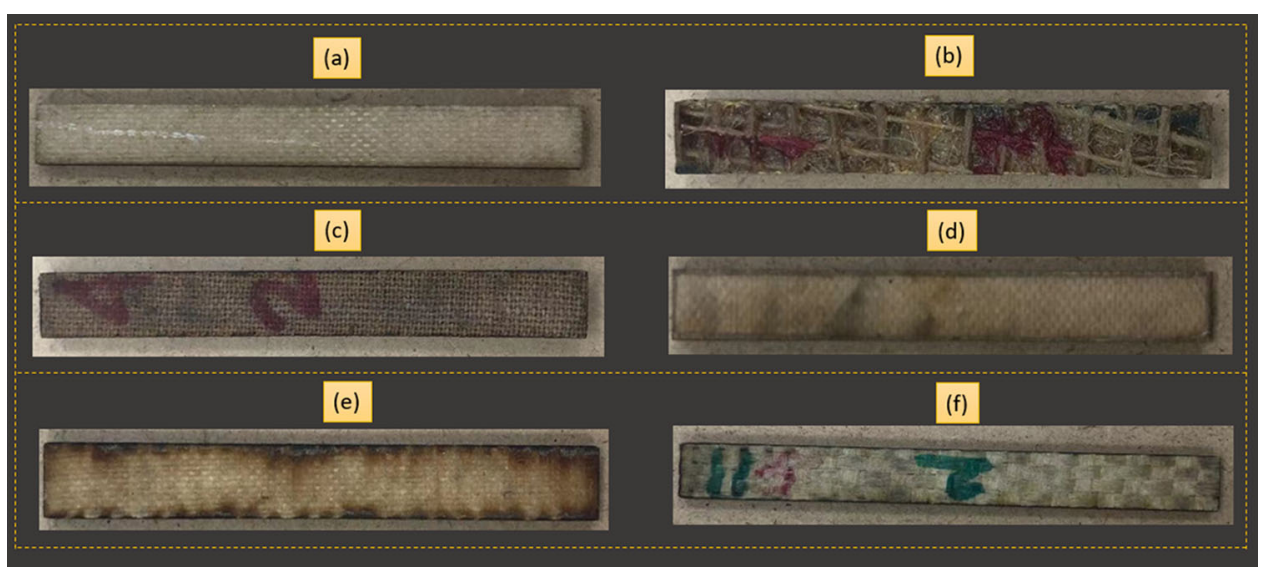

Figure 9 Composite samples from different woven fabrics developed in our laboratory: a flax woven fabric-reinforced PP composites, $\mathbf{b}$ jute woven fabric-reinforced MDI composites, c flax woven fabric-reinforced MDI nanocomposites (AgNP

sheet, yarn, fabric, or web structure in nonwoven fabrics to provide structural stability. Fibers of different origin and properties or a combination of both are brought together by employing nonwoven technology to produce composites from nonwoven fabric. Recently, some recycled materials (such as waste fabrics) are also used to form nonwoven fabrics by using the needle punch method through compression molding. In addition to the application of nonwoven fabric-based composites, nonwovens are also used for geotextiles, filtration, medicine, and acoustic purposes. Researchers also report some efforts for preparing nonwoven composites from kenaf, polypropylene, and fruit bunch [80]. With nonwoven fabrics, the conversion of fibers into yarns is not required to make the fabric like woven/knit. Nonwoven reinforced composites are widely used for non-structural parts of automobiles. The selection of composite type is highly significant especially for the high-velocity and low-velocity impacts of crash performance. Sometimes, the damage may not be seen at the composite surface, but the delamination and cracking could be imparted inside. The collision of tools due to lack of maintenance and exploitation conditions may create low-velocity impacts during the manufacturing of composites [81]. Fibrous composites are applied significantly in products such as vehicles, pipelines, aircrafts, sporting items, protective devices (personal), and in lightweight constructions.

Nonwovens are made with an assembly of soft, voluminous, and porous materials, but provide a loaded), d flax woven fabric-reinforced PLA composites, e hemp/glass woven fabric-reinforced epoxy composites, (a) glass/flax woven fabric-reinforced MUF composites.

support for mechanical damage. Previously, nonwovens were considered as low-cost replacements for conventional textiles; however, they are now used in technical, medical, and consumer products with diversified potential applications in terms of economic perspectives. The tensile elongation and strength of the composites from nonwoven fabrics are strongly influenced by fiber content and fabric direction [80]. The composites made from nonwoven fabrics can supply efficient engineering solutions through the manufacturing of multifunctional products by replacing several products with a single one, thereby providing an economically feasible aspect as well.

\section{Classifications of composite nonwovens}

Composites from nonwoven fabric can be broadly classified in following categories:

Complex nonwoven reinforced composites (NRC) The composites are formed by needle-punching, thermo-bonding/stitching, hydroentangling, and latex-bonding through bonding with nonwoven fabric or two and more webs.

Laminated NRC Nonwoven fabrics are combined with two or additional layers to form a stable single layered laminated composite by using adhesive or thermal treatment. The laminated NRCs are stronger than complex NRCs in terms of internal bonding. However, if the bonding is not adequate for technical reasons, separation of the sheets could be challenging. 
Blended NRC The fibers are of different origins but have similar characteristics or dissimilar characteristics but different origins or with a combination of both are mixed together to produce technologyblended NRCs.

Technology combined NRC Different technologies of web-bonding or web forming or a combination of both are used to manufacture technology combined NRCs.

Coated NRC Coating materials (biocides, abrasive particles, antimicrobials, metal ions, activated carbon, preservative agent, super absorbent, and so on) are applied on both or single surface of composites either permanently or temporarily to provide various functionalities.

Hybrid NRCs Knitted, braided, and woven fabrics, foams (with tissue), and films are combined with the nonwovens to develop a tri-layer composite by hydroentangling one woven fabric sheet between two nonwoven sheets.

\section{Composites from knitted fabric}

Knitted fabrics have opened a new branch of fabricreinforced composites comprising the yarns laid into a 3D stitching system and held tightly between the looped yarns in the fabric in assembly. Knitted fabricreinforced composites (KFRCs) have some special benefits when compared to the conventional designs. These benefits include lower thermal expansion, lower production costs, simple recycling, and high resistance against corrosion. KFRCs have potential applications for helmets (bulletproof), rescue tents, air ships, inflatable boats, and roofing membranes. KFRCs are soft composites, so they could be easily utilized for applications where the tearing and tensile characteristics are of prime concern [82]. Knitted fabrics are composed of course and wales yarns made through knitting process. However, when the fabrics are transformed into composite materials, both the course and wales directions of fabrics showed an improvement in strength with the increased loop density, which showed an agreement with the finite element model analysis [83].

\section{Polymers used for laminated composites preparations}

The polymeric matrixes are the base chemical reagents for binding laminated fabric materials together. As with other composite materials, fabricreinforced composites could also be prepared with thermoplastic, thermosetting, and cementitious materials. Recently, bio-based polymers like thermoplastic styrene elastomers, PLA, poly(hydroxy urethane), polyhydroxyalkanoates, and PHBV (poly(3hudroxybutyrateco-3-hydroxyvalerate)) have drawn attention due to their enhanced sustainability [84-88]. However, some synthetic polymers like PP (polypropylene), PE (polyethylene), and PVC (poly (vinyl chloride)) are frequently used by manufacturers [86, 89]. Furthermore, thermoset polymers are unsaturated polyester, polyurethane, epoxy, phenolics, MUF (melamine-urea-formaldehyde), and silicone [18, 90-95]. On the other hand, PP, PE, PVC, PS (polystyrene), and polyamide are some of the examples of thermoplastic polymers [86, 89, 96]. All of these chemicals possess distinct structures and groups, which enable them to function as strong binding agents in composite systems. Furthermore, both thermoset and thermoplastic polymers contain some advantages and disadvantages. Together with lower viscosity, thermoset polymers are suitable to facilitate the composites with better wetting of constituent fibers. Conversely, thermoplastic polymers are easy to post-form and recycle. However, thermoset polymers are brittle in nature. Unlike thermoset polymers, they are not recyclable and postformable. Furthermore, thermoplastic polymers require a higher temperature than the melting temperature as the melt flow is low. However, thermoset polymeric laminated composites could be processed even at room temperature.

\section{Finite element analysis on fabric-based composites}

Mechanical and thermal properties of the composites have received special attention in the composite materials sector. However, the prediction of the properties is drawing great interest through the use of various analytical and numerical modeling techniques [97-108]. A schematic model of laminated composite where Green et al. [109] described 
different processing steps of woven fabric laminated composites is shown in Fig. 10. The same study [109] also considered textile geometry before predicting the fabric-reinforced composite mechanical properties. However, it is difficult to predict the mechanical performances of fabric-reinforced composite for the complex mechanisms of fibers in the yarn and yarn in the fabrics [110]. Wang et al. conducted a study on braided composite where they also showed the yarnlevel delamination in composite systems for sports protection applications [111]. Crack propagation between the matrix and yarn in laminated composite system is shown in Fig. 11. Wang et al. also stated that shear stresses caused crack propagation and associated delaminations [111]. Furthermore, the outplane and in-plane deformations also exert significant influence on the mechanical deformations of laminated composites [110]. Moreover, the deformation mode is also responsible for determining the ultimate composite performances. FEA has become a prominent software-based technology for predicting the performance of the materials. The software also allows for the implementation of necessary corrective initiatives to achieve expected performances. A failure mechanism against applied loads/stresses as per FEA analysis is illustrated in Fig. 12. The mechanism saves a great deal of time, effort, and workload by providing the prediction of possible performances before the start of production.

De Carvalho et al. [112] demonstrated different failure locations upon maximum stress criteria
(Fig. 12) whereas physical-based criteria displayed different failure locations. Chen at el. [113] developed laminated hybrid composite from unidirectional woven fabrics for ballistic performances and simulated the fabrics in yarn level as having a density of 6.73 threads/cm both in lengthwise and crosswise directions and fabric density 240 GSM. The fabric was modeled $10 \times 10 \mathrm{~cm}^{2}$ symmetrically in $\mathrm{X}$ and $\mathrm{Z}$ axis. The projectile velocity toward laminated composite was $500 \mathrm{~m} / \mathrm{s}$ and the coefficient between the yarns was 0.14 [113]. The ballistic performance was measured as per Eq. 1.

$\Delta E=\frac{1}{2} m\left(v_{1}^{2}-v_{2}^{2}\right)$

where $\Delta E$ is loss of kinetic energy by projectile, $\mathrm{m}$ is projectile mass, $v_{1}$ is impact velocity, and $v_{2}$ is residual velocity of the projectiles. Finally, the FEA model was validated against the experimental data. The experimental results revealed that $0.053 \mathrm{~J} / \mathrm{g} \mathrm{m}^{-2}$ energy was absorbed by one layer woven fabrics, whereas unidirectional woven fabrics (single layer) showed $0.047 \mathrm{~J} \mathrm{~g} \mathrm{~m}^{-2}$ [113].

In order to understand the impact effect on composite structure, a mathematical model could be developed for the prediction of contact force history and structural performance of the composites. The modeling of structural composite projectile dynamics and the indention of respective structures in terms of projectiles were determined. In this regard, inelastic

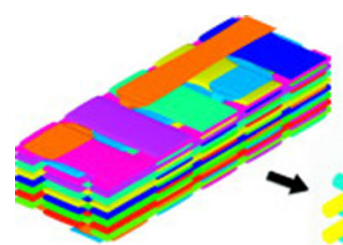

(a) Idealised geometry
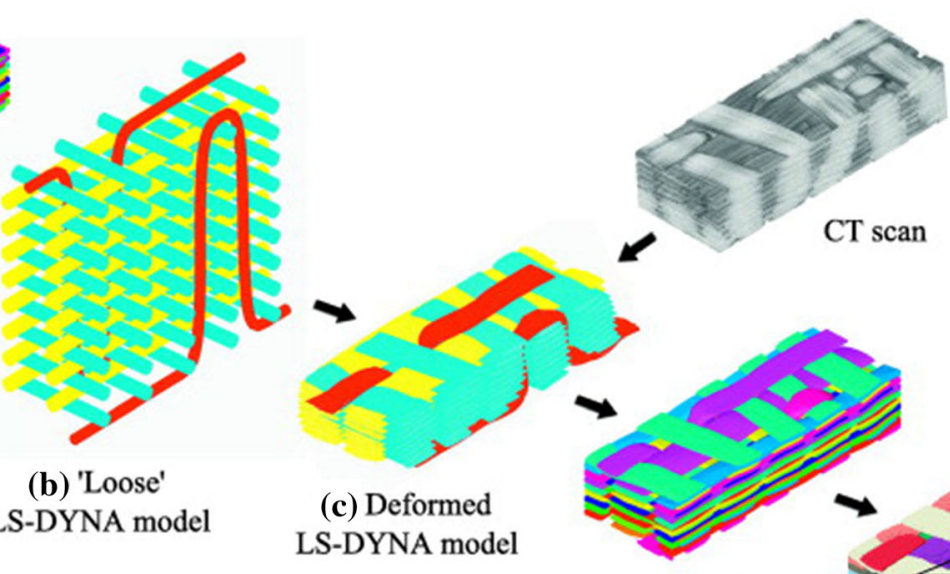

(d) Realistic geometry

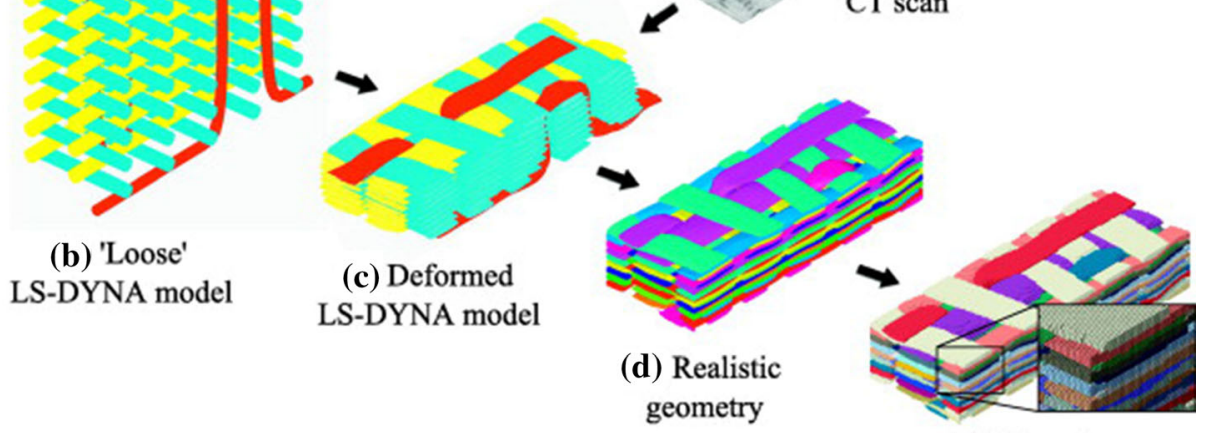

(e) FE mesh

Figure 10 Workflow modeling process overview in terms of CT scan photographs. Republished with permission from Elsevier [109]. Copyright Elsevier, 2014. 
Figure 11 Delamination and crack propagations $\mathrm{CT}$ scan photographs of braided composite plates at diverse impact energies: a $3 \mathrm{~J}, \mathbf{b} 6 \mathrm{~J}$, c $9 \mathrm{~J}$, and $\mathbf{d}$ crack propagation illustrations. Republished with permission from Elsevier [111]. Copyright Elsevier, 2017.
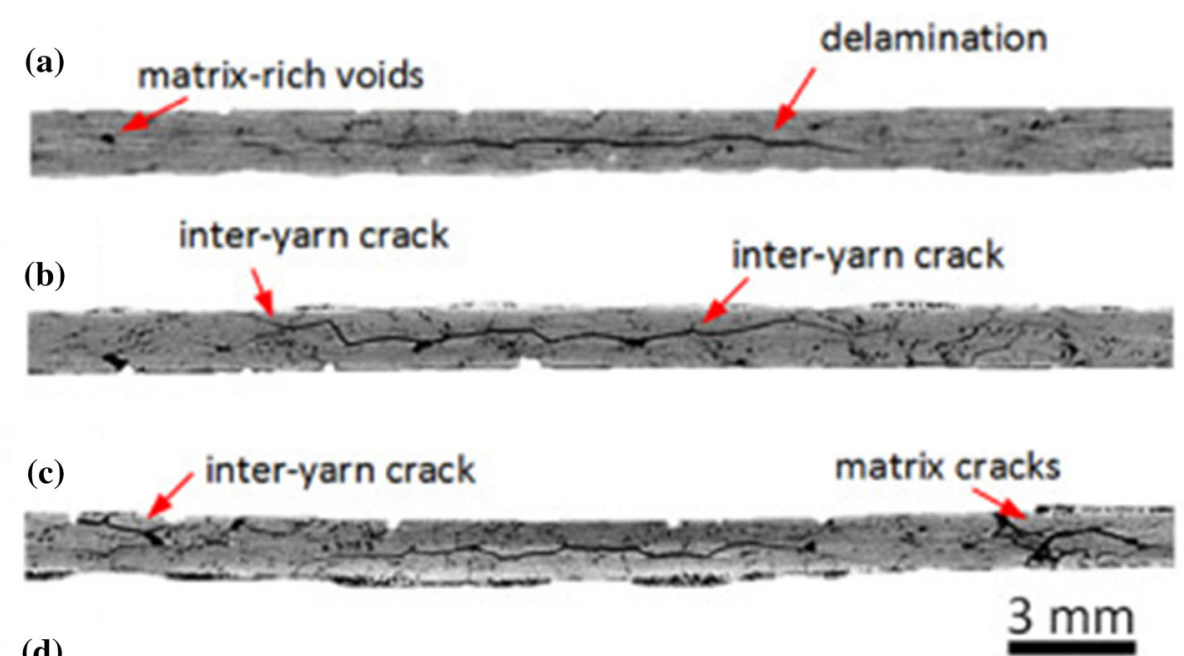

(d)

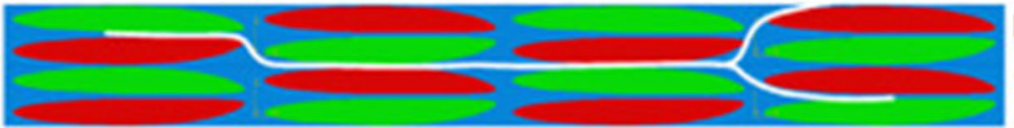

layer (interlacing) interfoce layer
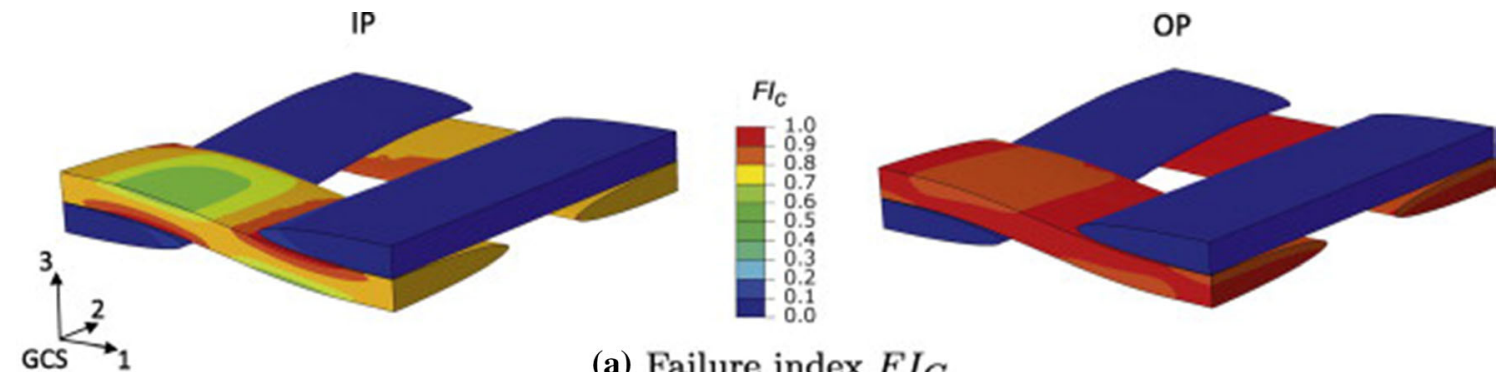

(a) Failure index $F I_{C}$
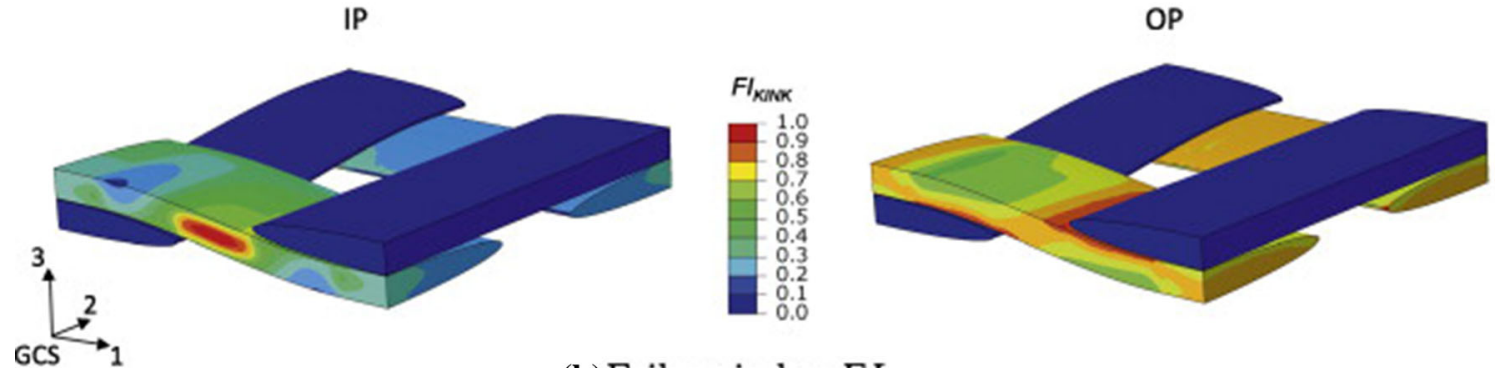

(b) Failure index $F I_{K I N K}$

Figure 12 Failure indexes at compression failure under two criteria: a maximum stress $\left(F I_{C}\right)$ and $\mathbf{b}$ physical-based $\left(F I_{K I N K}\right)$. Republished with permission from Elsevier [112]. Copyright Elsevier, 2017.

impact was studied by Lin et al. [56] as demonstrated by Eq. 2:

$m_{\mathrm{p}} V_{\mathrm{p}}=\left(m_{\mathrm{p}}+m_{n}\right) V_{0}$

where $m_{\mathrm{p}}$ indicate projectile mass, $V_{\mathrm{p}}$ initial velocity, $+m_{\mathrm{n}}$ stands for mass of the $\mathrm{n}$ node, and $V_{0}$ is the initial velocity of node (impacted). Later, the projectile is considered as mass added to $n$ node and dynamics of structures could be determined in terms of structural value problems.

Furthermore, micromechanical FEA is also getting attentions for characterizing composite materials through introducing adequate unit cells [114-119]. The unit cells could be formulated depending on the periodic conditions of respective problems. The boundary conditions are extremely important which 
needed careful considerations before going to FEA of the problems. However, the boundary conditions also sometimes based on as per the intuition of respective persons or sometimes subjected to the uniaxial tensions [118]. Nonetheless, shear loading also needed to consider which is not performed in so many cases generally as this is relatively difficult scenario. Moreover, the validation of unit cell is also very important. 'Sanity check' is also necessary for the formulated unit cell to compare with the experimental data although precise correctness is difficult to achieve. The thermal performances of the 3D braided fabric-reinforced composites could also be calculated effectively through employing FEA [120-122].

\section{Fabrication of laminated composites from different fabrics}

The production of fabrics for lamination is comparatively easier than other types of composites like fiber or particles. The hand-lay-up method is one of the most common and widely used fabrication methods for fabric lamination to produce composites due to the lost-cost manufacturing features. Recently, there were two types of laminated composites developed from our groups where flax and glass woven fabrics were the reinforcements and PLA, PP, and MDI were used as polymeric resin [123, 124]. In the case of flax/glass woven fabric/MDI composites, the MDI thermoset resin was sprayed over the stacked fabrics with a spatula and the lamination was created for six layers of fabrics. Later, the laminated fabrics were pressed by a pressing machine applying $3.50 \mathrm{MPa}$ load at room temperatures for $5 \mathrm{~min}$. The pressure was then released, and the laminated composites were cured at room temperature for $24 \mathrm{~h}$. In the case of flax woven reinforced thermoplastic polymeric composites, initially the PLA and PP sheets were prepared by applying high temperatures $\left(170{ }^{\circ} \mathrm{C}\right.$ for PLA and $180^{\circ} \mathrm{C}$ for PP). Later, the flax woven fabric, PLA and PP sheets with specific dimensions were laminated and hot-pressed again to produce the flax/ PLA and flax/PP laminated composite panels. Monteiro et al. [125] developed fique (a special type of fabric) woven fabric-reinforced composites for armored vest applications. In this regard, they [125] dried the fabrics first and then poured the thermoset resin in the differently layered fabric stackings and pressed them $(3 \mathrm{MPa})$ at room temperature $\left(25^{\circ} \mathrm{C}\right)$ for $24 \mathrm{~h}$. Rouf et al. [126] developed laminated composites from eight plies of woven fabrics through implementing VARTM (vacuum-assisted resin transfer molding) methods. During this processing, all the plies were placed in zero degree directions. However, the asymmetric design was dominated by warp yarns in one face, whereas weft yarns were kept in another face. Moreover, the curing was conducted for $24 \mathrm{~h}$ at room temperature as well [126]. A schematic design of laminated composites is shown in Fig. 13.

\section{Mechanical performances}

The mechanical properties of composite are significant performance characteristics that require testing to examine the performance suitability of the products. Generally, the mechanical properties are investigated in terms of tensile, flexural, impact, and compressive properties. The mechanical properties depend on many factors like yarn geometry in fabrics, fiber types (natural or synthetic), matrix used for reinforcements, fabrication methods, heating/cooling rate for thermoplastic polymeric materials, and so on. Moreover, the chemical cross-linking, morphology, molecular weight, number of plies, fabric properties (like density, thickness, yarn count, etc.) also greatly influence developed laminated composite panels. The mechanical properties of different fabric-reinforced laminated composites are tabulated in Table 1.

\section{Tensile properties}

Tensile test measures the force required to break the test specimen (Figs. 14, 15) of composites and associated elongations at breaking point. Tensile properties in terms of tensile strength, modulus, breaking strength, elongation at break, load versus displacement curves are considered as the most important characteristics to discuss laminated composite performance behavior [86, 140]. Furthermore, Poisson ratio, ductility, and yield strengths could also be determined through tensile strength characterizations. The tensile tests are conducted as per different standards like ASTM D 638, EN 310, ISO 527-4, ISO 527-5, ASTM C 297, ASTM D 3039, and ASTM D 638 as per the requirements [141-144]. Tensile strengths of the laminated composites provide higher strengths 
Fibre angle

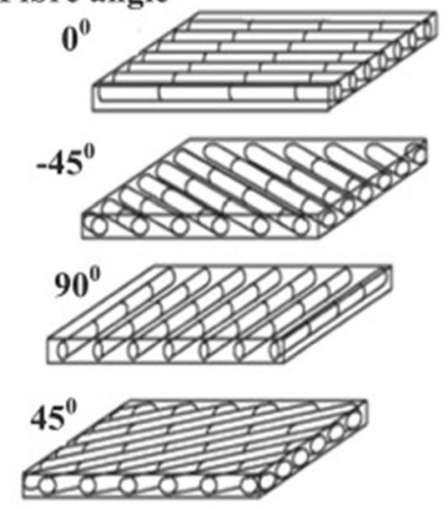

(a)

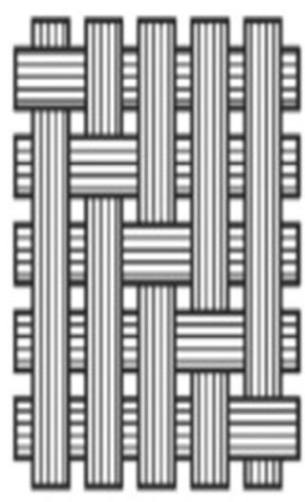

(b)

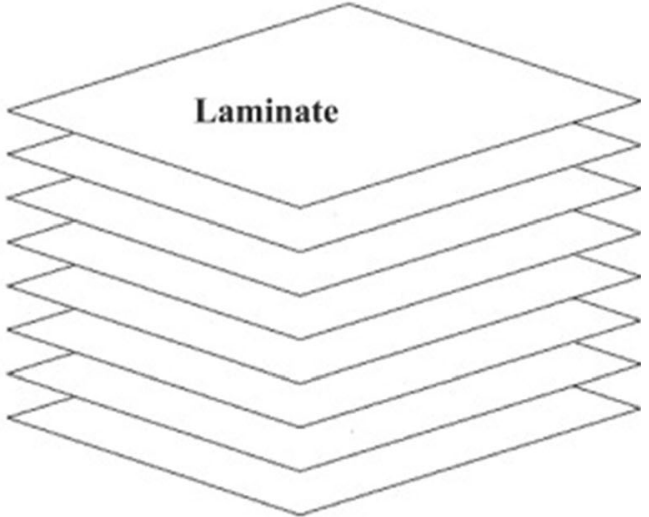

(c)

Figure 13 Fabric laminated composites: a orientation of ply, b satin weave, and c laminated ply (8-layer). Reprinted with permission from Elsevier [127]. Copyright Elsevier, 2016.

Table 1 Mechanical properties of fabric-reinforced laminated composites

\begin{tabular}{|c|c|c|c|c|c|c|}
\hline Laminated composites & TS (MPa) & $\mathrm{E}(\mathrm{GPa})$ & MOR (MPa) & MOE (MPa) & IS $(J / m)$ & Ref. \\
\hline Glass woven fabric/epoxy & 346.6 & 1.28 & 318.75 & 20.83 & 1470.5 & [128] \\
\hline Sisal woven fabric/epoxy & 33.2 & 0.20 & 124.64 & 7.70 & 147.1 & [128] \\
\hline Sisal/glass woven fabric/epoxy & 108.22 & 0.53 & 205.64 & 12.72 & 635.5 & [128] \\
\hline Cotton/cotton woven fabric/epoxy & 72.92 & - & 82.08 & - & - & [129] \\
\hline Cotton/bamboo woven fabric/epoxy & 85.37 & - & 107.02 & - & - & [129] \\
\hline Flax woven fabric/epoxy & 91.07 & 1.96 & 109.5 & 6.39 & 295.65 & [130] \\
\hline carbon woven fabric/epoxy & 406.6 & 15.2 & - & - & - & [131] \\
\hline Carbon/Jute woven fabric/epoxy & 257.6 & 9.8 & - & - & - & [131] \\
\hline Hemp woven fabric/vinyl ester & $46.61-56.3$ & $5.81-6.19$ & $77.13-90.54$ & $4.28-5.07[132]$ & - & $84]$ \\
\hline Kenaf/carbon woven fabric & 117 & 7.21 & 224 & 7.68 & - & [133] \\
\hline $\begin{array}{l}\text { Ramie woven fabric } \\
\text { Knit fabric }\end{array}$ & $67.86 \pm 1.71$ & - & $104.93 \pm 3.2$ & - & - & [134] \\
\hline Co-woven knit fabric & $606.72 \pm 55.4$ & $24.17 \pm 2.01$ & - & - & - & [135] \\
\hline Bamboo/cotton knit fabric/epoxy & - & - & $140.44 \pm 6.02$ & $6.89 \pm 0.523$ & - & [136] \\
\hline Modal/cotton knit fabric/epoxy & - & - & $192.83 \pm 12.90$ & $10.69 \pm 0.95$ & - & [136] \\
\hline $\begin{array}{l}\text { Viscose/cotton knit fabric/epoxy } \\
\text { Nonwoven fabric }\end{array}$ & - & - & $173.25 \pm 13.13$ & $9.14 \pm 0.43$ & - & [136] \\
\hline Jute woven/nonwoven/polyester & 25.09 & - & 2.83 & - & - & [137] \\
\hline Nonwoven kenaf/polyester & $251.43 \pm 49.29$ & $17.39 \pm 5.36$ & - & - & - & [138] \\
\hline Nonwoven flax/PLA & $90.4 \pm 7.8$ & $13.2 \pm 1.3$ & - & - & - & [139] \\
\hline Nonwoven flax/PHA & $82.4 \pm 4.1$ & $10.3 \pm 1.5$ & - & - & - & [139] \\
\hline Nonwoven flax/PP & $59.4 \pm 2.1$ & $8.2 \pm 0.7$ & - & - & - & [139] \\
\hline
\end{tabular}

TS Tensile strength, E Elastic modulus, MOR Modulus of rupture, MOE Modulus of elasticity, IS Impact strength

especially in parallel directions compared to other types of directions. In one of our recent studies, we also found similar effects for flax or PLA and PP composites where strengths in warp direction were higher than weft directions for both types of matrices [145]. The failure of composites against applied load is depicted in Fig. 15.

\section{Flexural properties}

Flexural properties (strength and modulus) are another important parameter for demonstrating the mechanical characteristics of laminated composites. The test is performed against a three point bending load on the composite specimens (Fig. 16). The 
flexural modulus indicates the stiffness of composite specimens. The flexural properties of the materials could vary according to temperature; hence, the maintenance of ambient temperatures is needed to obtain optimum results. There are different testing methods like ASTM D790 and ISO 178 that are followed for flexural properties analysis [147]. The chemical structures of fibers in constituent laminates

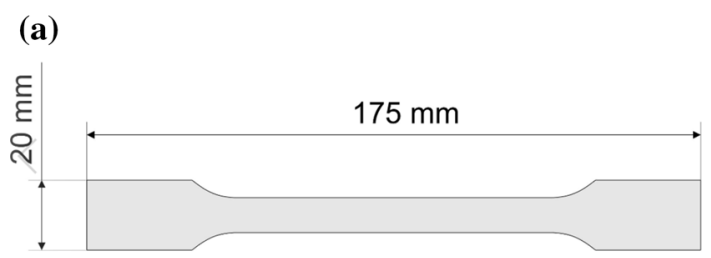

(b)

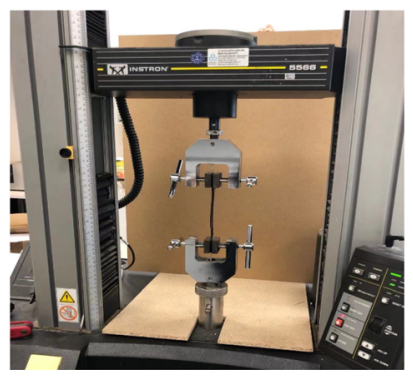

Figure 14 A schematic representation of tensile test: a samples for tensile test and $\mathbf{b}$ sample placed in Instron testing equipment. Drawn by Péter György Horváth. also greatly influence the flexural properties. In the case of natural fibers, if the cellulosic content and degree of polymerization is higher, then the flexural properties would also be higher [148]. Ries et al. [149]conducted an experimental analysis on flexural characteristics of laminated hybrid composites as per Fig. 16 setup.

The modulus of rupture (MOR) is calculated as per Eq. 3, where $F$ indicates maximum load/force, 1 is span length $(\mathrm{mm}), b$ is specimen width, $t$ is thickness, and $a$ is deflection.

$\mathrm{MOR}=\frac{3 F l}{b t^{2}}$

MOE, $E_{\mathrm{m}}=\frac{l_{1}^{3} \times\left(F_{2}-F_{1}\right)}{4 b t^{3} \times\left(a_{2}-a_{1}\right)}$

MOE (Eq. 4) demonstrates modulus of elasticity, $l_{1}$ is span support, increased load $(N)$ on the straight direction of the curve $\left(F_{2}-F_{1}\right) . F_{1}$ stands for $10 \%$ of $F_{\max }, F_{2}$ stands for $40 \%$ of $F_{\max } \cdot a_{2}-a_{1}$ is the increased deflections measured from sample center related with the increased load $F_{2}-F_{1}$. This explanation was also reported in our previous research on flax woven fabric reinforced with PLA/PP thermoplastic polymers and cement-bonded fiber composite panel [140, 150]. Furthermore, a failed propagation
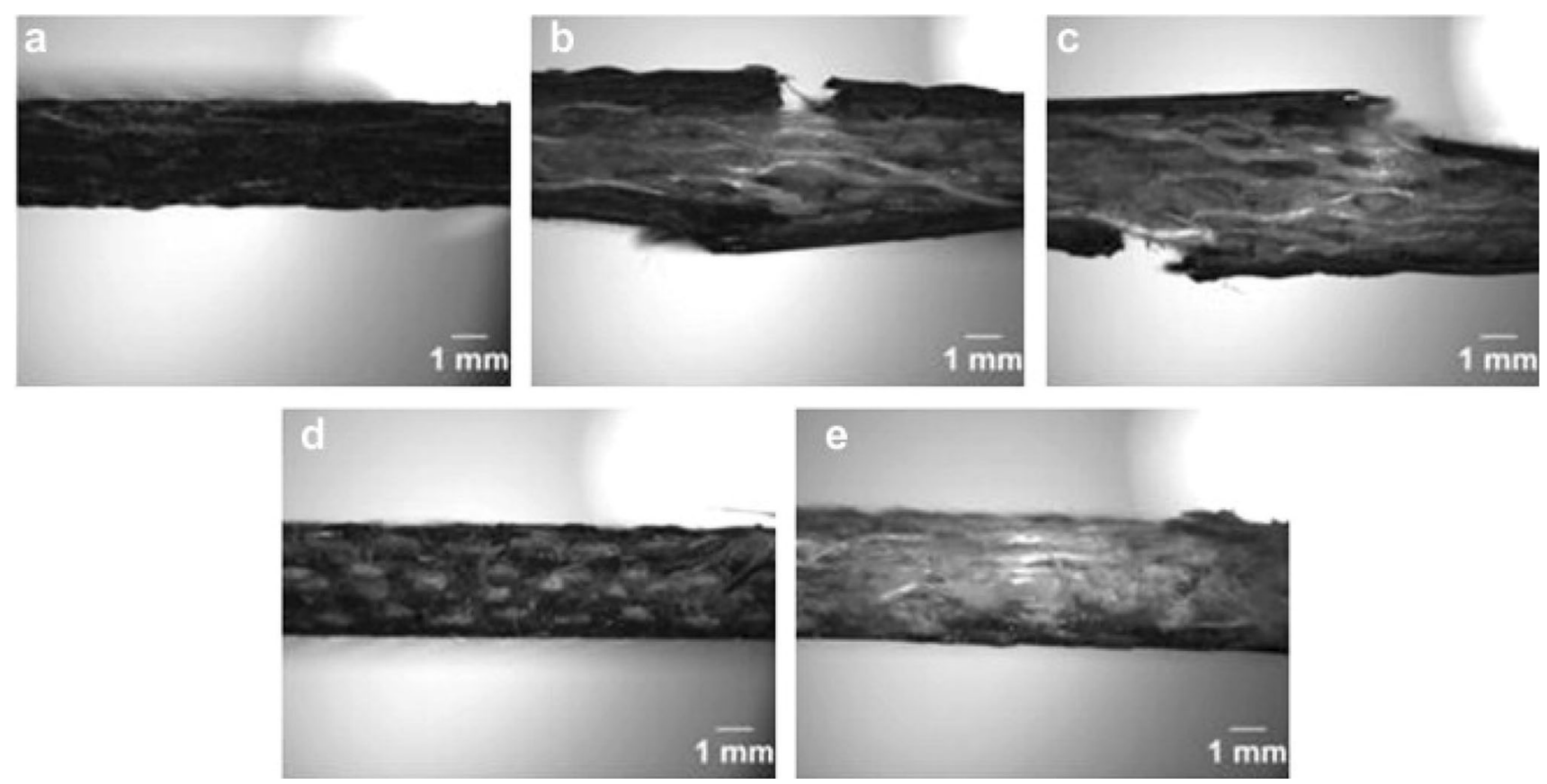

Figure 15 Microscopic photographs of failed laminated composites against tensile loading (a-d). Reprinted with the permission from Elsevier [146]. Copyright Elsevier, 2012. 


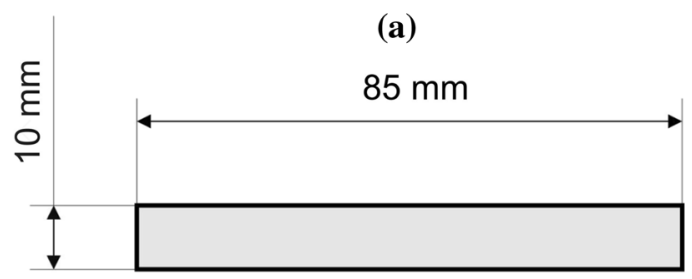

(b)

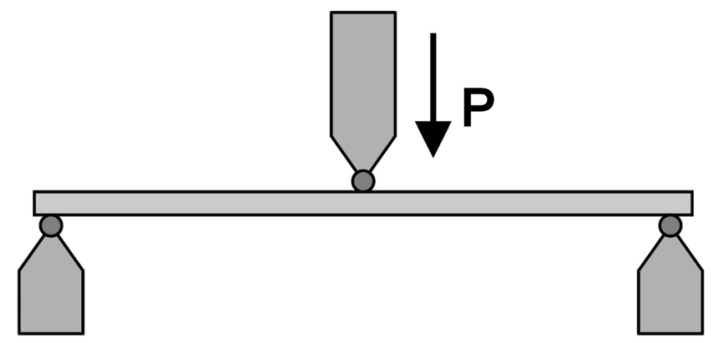

(c)

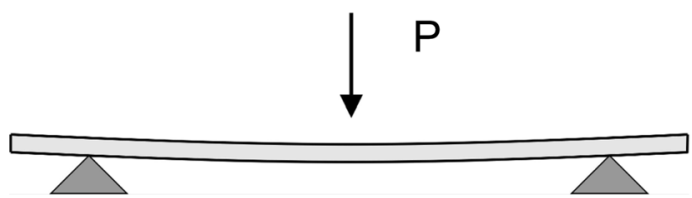

Figure 16 Flexural test: a samples geometry, b schematic diagram of three point flexural test design and place samples in the system, and c schematic diagram of bent samples during the test. Drawn by Péter György Horváth.

against flexural loading on laminated composite is shown further in Fig. 17.

\section{Impact strength}

Typically, an impact test demonstrates the response of a material upon sudden load applied to the specimen (Fig. 18). An impact test could also be utilized to discover the energy absorbed by the samples during the fracture of composites. Furthermore, an impact test is also popularly used for evaluating the brittleness, toughness, and notch-sensitivity in addition to the impact strengths [142]. The impact properties of the composites also depend on the fiber types and interlaminar shear strengths. The laminated composites exposed more vulnerability against impact damage compared to other structural materials. Likewise, smaller debris and stones could be propelled from the highway during aircraft departures and landings at higher tire velocity. It may happen with larger projectile velocity, although the velocity becomes lower. Furthermore, breakage/delaminations of fiber and cracking of matrix could also occur for structural laminates due to the lower velocity of the impact loading during the use/functioning of the materials. Moreover, catastrophic damage may also happen through the internal damage/failure of the composites. In this regard, it is essential to investigate the capabilities of energy absorption and impact resistance properties of the laminates before using them for particular applications. However, through preventing the ultimate failure of composites from structural laminates, such problems could be solved/improved [151]. Furthermore, stress distribution could be tuned by controlling the stiffness of fibers during the impact loading in composite systems. Impact strengths could be measured with the Charpy and Izod tests. However, there is a slight difference between these tests as the Izod test requires placing the notch facing striker [142]. Overall, impact tests ensure the safety and liability of the composite materials and are, therefore, a highly significant characterization.

\section{Compression test}

The buckling of composite materials is tested in terms of compression characterizations. Laminated panels are tested for compression where the samples are comparatively thinner, flat, and rectangular. The behavior of composite materials is characterized against crushing load, and the associated deformations and compressions are noted to calculate the stress and strain (compressive) upon different loads. Generally, there are three methods of introducing the compressive load on test specimen: (a) end load, (b) shear load, and (c) combined load [142]. The end load is applied into the flat end, shear load into wide faces, and combined load at the combination of end and shear load on a composite specimen [142]. Some of the commonly used compression methods are ASTM D 3410, ASTM D 695, ISO 14,126 [152-154]. The failure pattern of impacted and non-impacted buckling composite samples is illustrated in Fig. 19 where the buckling lines could be easily observed in both cases.

\section{Thermal property}

Thermal stability of the laminated composites is a highly crucial parameter that could be investigated in terms of TGA (thermogravimetric analysis), DTG 

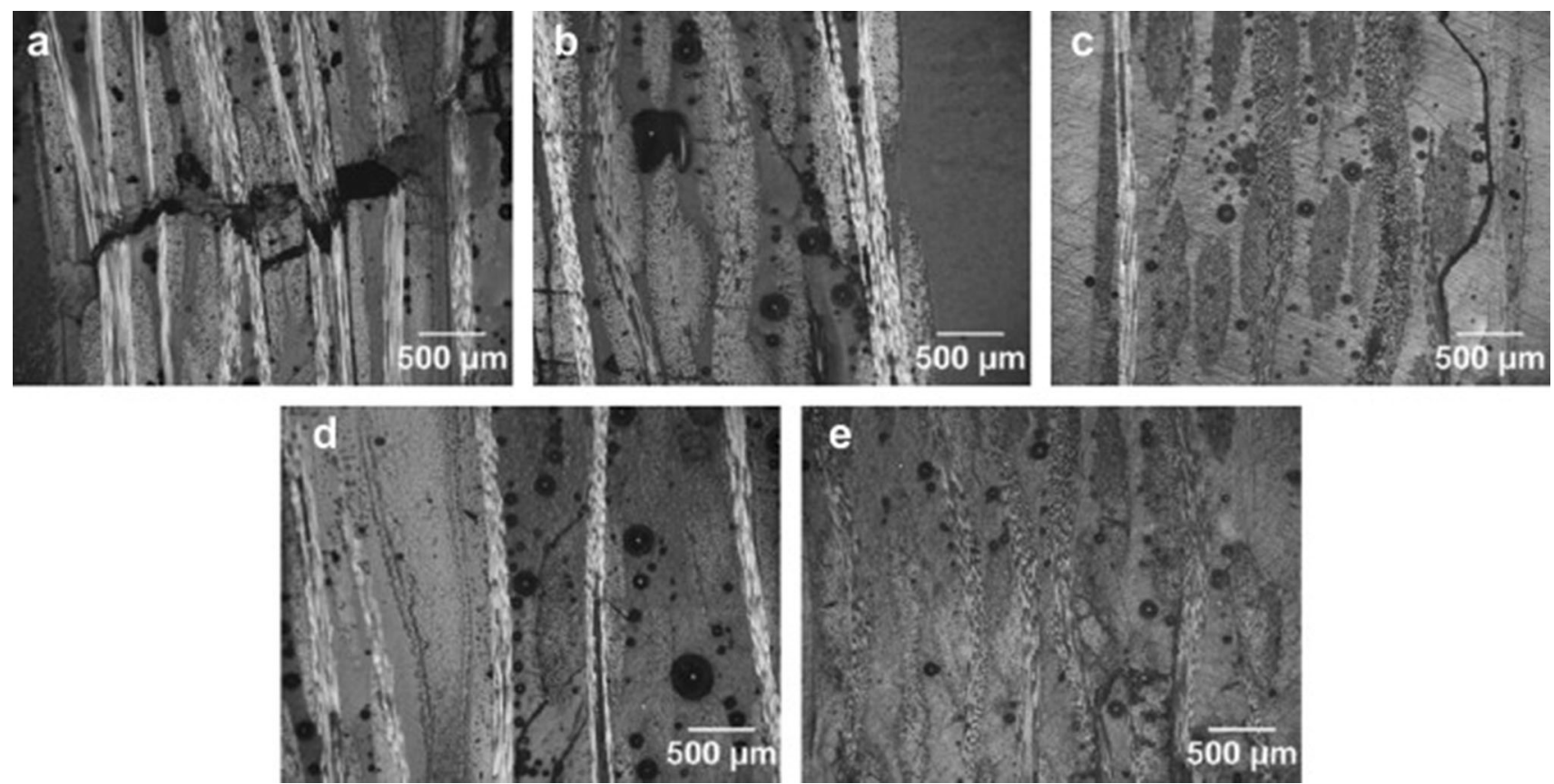

Figure 17 Microscopic photographs of failed laminated composites against flexural loading (a-d). Reprinted with permission from Elsevier [146]. Copyright Elsevier, 2012.

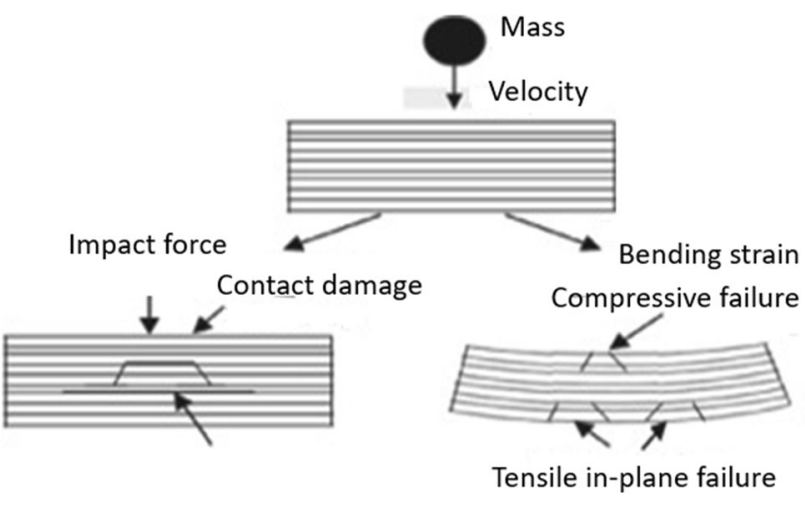

Figure 18 A drop-weight schematic diagram of impact damage. Reprinted with the permission from Elsevier [127]. Copyright Elsevier, 2016. (derivative thermogravimetric, and DSC (differential scanning calorimetry) analysis. Kannan et al. [156] performed a study on flax interwoven fabric reinforced with PP composites. In the same study, they [156] found that control flax fabrics provided a threestep degradation (initially within $120-220^{\circ} \mathrm{C}$ for moisture evaporations, a second step within 345-380 ${ }^{\circ} \mathrm{C}$ for hemicellulose and lignin decompositions, and a final step after $578{ }^{\circ} \mathrm{C}$ displayed the complete weight loss). However, PP shows the decompositions at high temperatures (initial and final) at 372 and $431{ }^{\circ} \mathrm{C}$, respectively [156]. However, the loading of flax with PP improved the thermal stability of flax fabrics where the initial degradations
Figure 19 Failure pattern of impacted and non-impacted buckling composite samples. Reprinted with permission from Elsevier [155]. Copyright Elsevier, 2013.
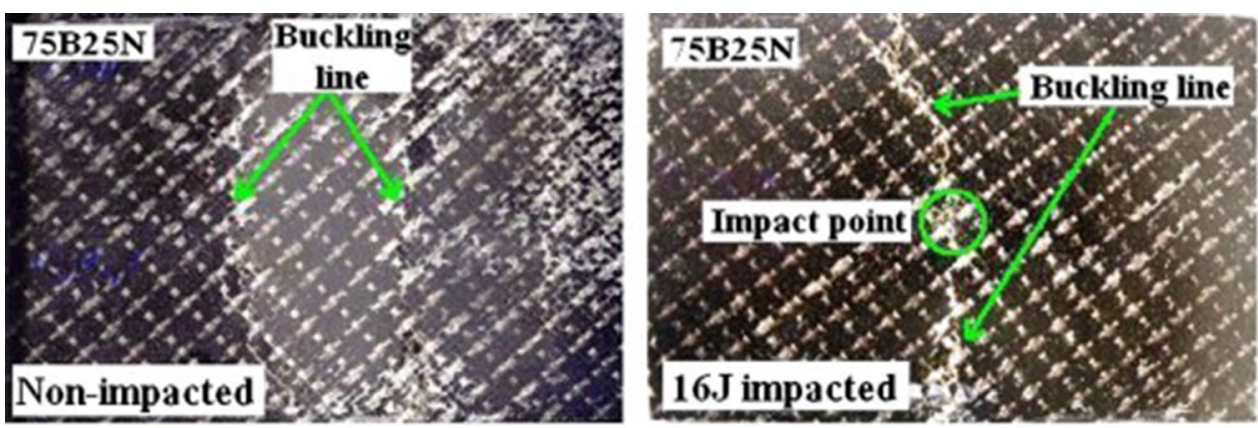

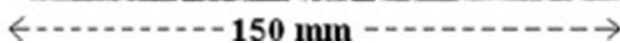


starts from $200{ }^{\circ} \mathrm{C}$, second step degradations at 333 to $375^{\circ} \mathrm{C}$, and final steps at $587^{\circ} \mathrm{C}$ [156]. On the other hand, woven fabrics from synthetic fibers like glass display more thermal stability compared to natural fiber like flax woven fabric-reinforced polymeric (like MDI polymeric) composites [145].

\section{Morphological properties}

Surface morphology investigation is extremely important to understand the fiber to matrix compatibility as it determines the thermo-mechanical performances of laminated composites. However, interfacial bonding or fiber to matrix adhesion in the case of fabrics made of natural fibers could be improved by using pretreatment (like mercerization/ alkaline treatment) of the fabrics. Furthermore, if the fibers are incompatible with the polymers, there could also be a decline in mechanical properties with associated cracking, which becomes noticeable during the tensile stresses. The fracture could happen for a variety of reasons including irregular fiber distributions during the yarn and fabric formations, mixing of matured and immature fibers, arbitrary fiber lengths and nodes, and so on [140]. Moreover, the failure of composite system likely occurs because of fiber breakage in the laminate systems, too. The debonding of fibers from matrix system against tensile load is another major reason for composites failure [157]. To overcome the embrittlement in composite system, it is necessary to select the suitable polymers for the respective reinforcement materials. A failed section of composite is shown in Fig. 20 where the pulling out of fibers could easily be observed in the matrix systems.

\section{Physical properties}

Studying physical properties of laminated composite is important to investigate the dimensional stability of the developed materials. Water absorption, thickness swelling, and moisture content of laminated composites are considered as the principal physical properties. The water absorption of laminated composites entails the effect of moisture content characteristics of composites, debonding between the fiber and matrix, and associated strength loss [158]. Furthermore, higher water absorption and poor thickness swelling results in decreased mechanical properties [159]. The natural fiber-oriented fabric-reinforced polymeric composites provide higher moisture contents than artificial fiber-oriented fabricreinforced laminated composites because the natural fibers contain cellulosic polymers in their chemical structure $[145,160,161]$. The reason for the higher moisture contents of natural fiber-based [162] fabric composite is the presence of hydrophilic compounds like $-\mathrm{OH},-\mathrm{NH}_{2},-\mathrm{COOH}$, and $-\mathrm{CO}$ groups in their polymeric structures. Furthermore, the pretreatment of fabrics before composite formation could also lead to improved moisture content, water absorbency, and thickness swelling properties [163]. Water absorbency of the composite samples is measured as per Eq. 5, thickness swelling by Eq. 6 and moisture contents by Eq. 7 .

$W_{\mathrm{a}}=\frac{W_{\mathrm{w}}-W_{\mathrm{d}}}{W_{\mathrm{d}}}$

where $W_{\mathrm{a}}$ indicates water absorbency, $W_{\mathrm{d}}$ initial weight of specimens before submerging in water, $W_{\mathrm{w}}$ is the weight of specimens after being submerged in water.

$T_{\mathrm{s}}=\frac{T_{\mathrm{w}}-T_{\mathrm{d}}}{T_{\mathrm{d}}}$

where $T_{\mathrm{s}}$ indicates thickness swelling, $T_{\mathrm{d}}$ initial thickness swelling of specimens before being submerged in water, $T_{\mathrm{w}}$ is the thickness swelling of specimens after being submerged in water.

$M_{\mathrm{c}}=\frac{M_{\mathrm{b}}-M_{\mathrm{d}}}{M_{\mathrm{d}}}$

where $M_{\mathrm{c}}$ indicates moisture content, $M_{\mathrm{b}}$ initial weight of specimens before drying, $M_{d}$ is the weight of specimens after drying. A schematic representation of samples submerging under the water is displayed in Fig. 21.

\section{Hybridization of laminated composites}

Hybrid laminated composites are formed by reinforcing two or three fabric types (such as fabric from different natural/synthetic fibers like glass/flax, different natural fibers like flax/hemp, and different synthetic materials like glass/carbon) with the polymeric matrix. The hybridization of laminated composites could provide superior thermo-mechanical 
Figure 20 SEM photographs of fractured flax/epoxy composites: a control composite and $\mathbf{b}$ after exposure the composite to weather for $1500 \mathrm{~h}$. Adapted with the permission from Elsevier [157]. Copyright Elsevier, 2015.
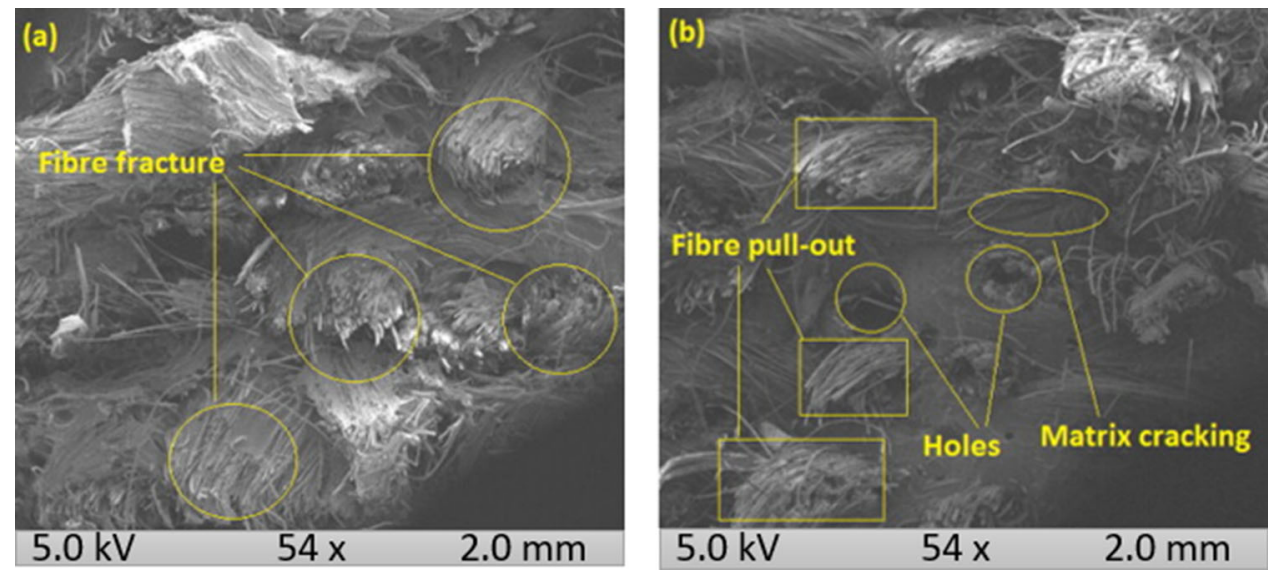

Figure 21 Schematic representation of water absorbency and thickness swelling test. Drawn by Péter György Horváth

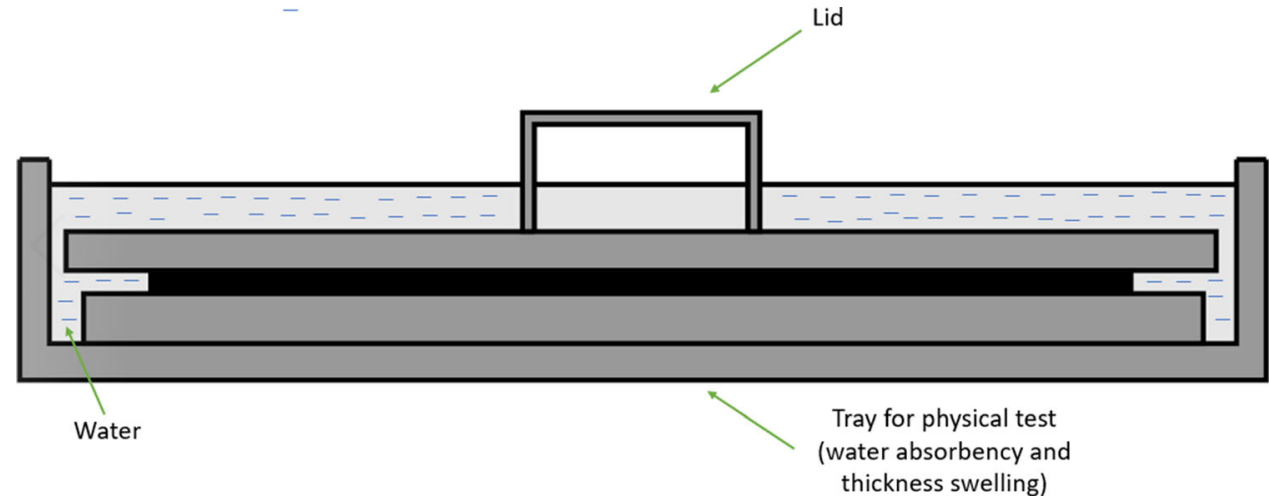

properties [145, 164, 165]. Sometimes, fabrics with lower cost and modulus are hybridized with fabrics possessing higher modulus and cost to minimize the product cost with enhanced performances. The world is becoming more sustainable and greener; hence, reinforcement of strong synthetic base material like glass/carbon fabrics with comparatively less strong naturally derived flax/hemp woven fabrics could provide a greener product with the presence of polymers. Generally, the hybrid composites could provide even higher thermo-mechanical properties compared to individual fabric-based composites $[140,145]$. Sometimes the natural and synthetic fibers can also be interwoven together (Fig. 22) to get the hybridized performances from ultimate composite products. Kumar et al. [166] conducted research on flax/glass woven fabric-reinforced vinyl ester composites with a different stacking sequence. In their study, they found that pure flax stacking (4 layers) provided $73.94 \mathrm{MPa}$ tensile strength and pure glass stacking (similarly 4 layers) provided $85.16 \mathrm{MPa}$ tensile strengths whereas their hybridized stacking (4 layers flax and 3 layers glass, in total 7 layers)

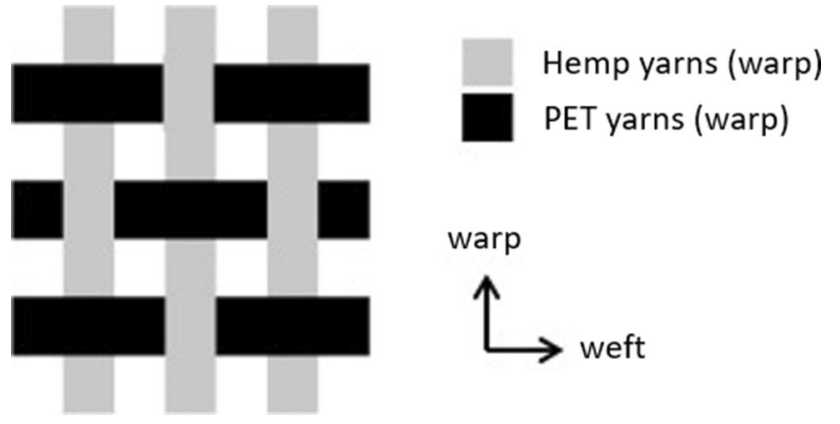

Figure 22 Direction of warp and weft for interwoven hybrid composite. Republished with permission from Elsevier [55]. Copyright Elsevier, 2018.

provided the highest tensile strengths (143.21 MPa) [166]. The results clearly demonstrated that glass woven fabrics have higher strengths compared to natural flax; however, their hybridization could generate even higher tensile strengths than their individual contributions. The same study by Kumar et al. also found improved thermal behavior from their hybridized composites whereas pure glass contains highest thermal stability. Pure flax lowers stability, but all the hybrid composites were found to 
have stability between the glass and flax (Fig. 23). Overall, it could be summarized that the hybridization of laminated composite displays new potentiality with improved mechanical performances.

\section{Recent developments in fabric-based products}

The composites sector is drawing increased attention for implementing state of the art technologies to improve performance and minimize processing costs by maintaining environmental sustainability. The implementation of FEA is also one of the prominent technologies for predicting performance, which could efficiently facilitate the minimizing of raw material usage and design from the operation protocols. The pretreatment of reinforcement [86] fabrics could also play a considerable role in developing thermo-mechanical performance by increasing fiber to matrix interactions. However, feasible pretreatment methods are limited; hence, more research to explore suitable routes of treating the fabrics in advance before laminations are needed. Laminated composites are becoming increasingly appealing for their superior application potentiality with multifaceted diversifications. However, the huge variation in knitting, weaving, and bonding could be tuned to bring a positive reinforcement attribution in the laminated composites through applying FEA. Furthermore, as laminated composites are gaining popularity for sensitive application areas like aerospace, researchers and manufacturers are also focusing on investigating and understanding the fracture behavior/failure mode of the laminations in composite systems. However, cracking could be identified by applying different methods such as finite element analysis, shear log model, and so on [167]. Typically, stiffness of the reinforced fabric materials is much higher compared to the polymeric matrix. Nevertheless, a considerable strain magnification occurs on the matrix system when the load is applied in transverse directions. Generally, the cracks are developed in off-axis directions [167]. Furthermore, due to the mismatching in-plane of composites transverse and longitudinal Poison ratio, the fracture could appear in longitudinal directions. Moreover, overall behavior and performances of the laminates are dependent on the cracking of matrix and internal damage against the applied load. In addition, modulus of laminates also declines significantly. Conversely, the residual thermal stress could be significantly developed at the curing stage, especially for synthetic/natural fiber-reinforced hybrid
Figure 23 Thermal

characteristics

(thermogravimetric analysis)

of hybridized laminated

composites: PG- $100 \%$ glass,

PF- $100 \%$ flax, FG1 to FG5-

different volume fractions of

flax and glass. Reprinted with permission from Elsevier

[166]. Copyright Elsevier,

2019.

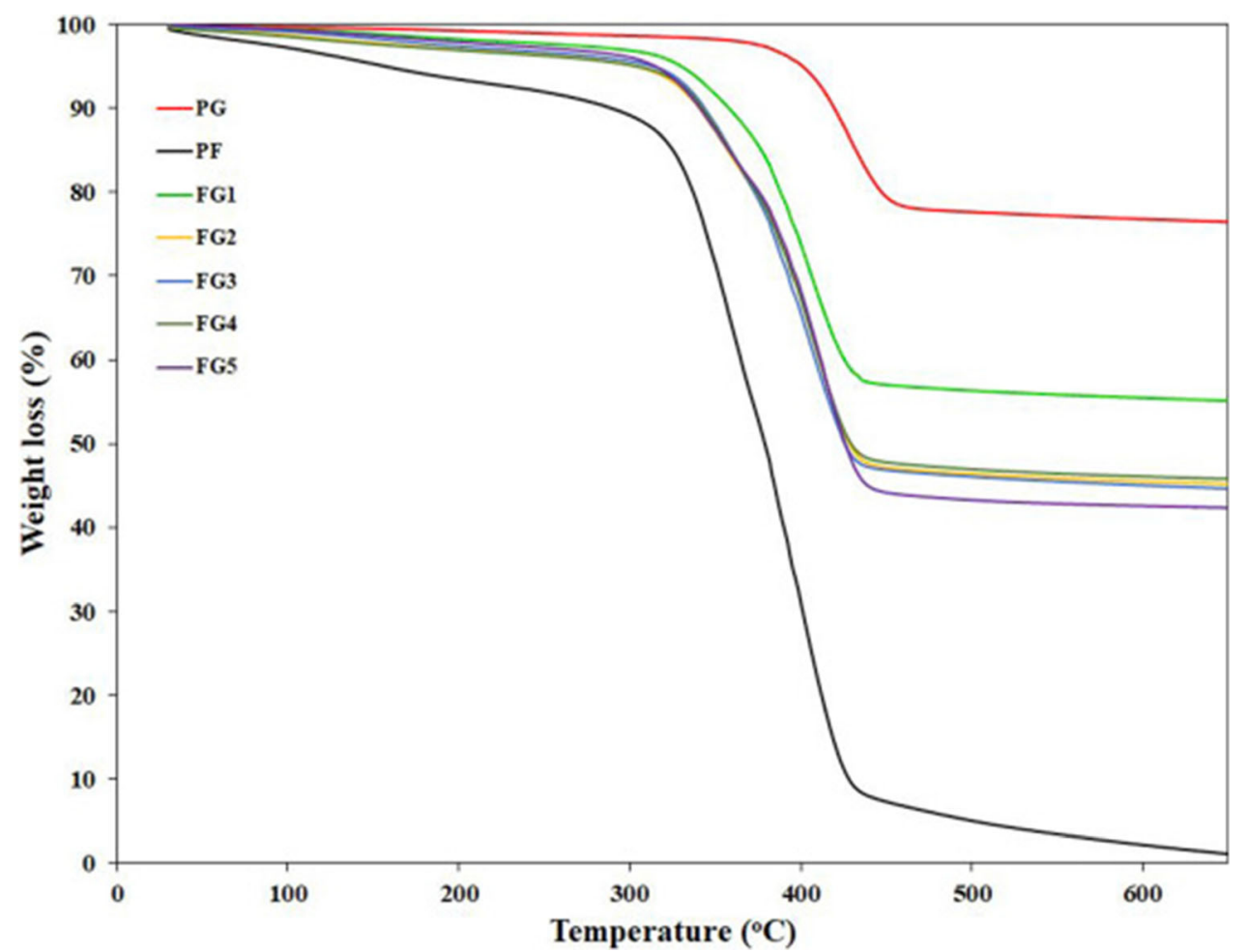


composites like carbon/epoxy laminates. The utilization of waste materials from textile and clothing industries is also gaining potentiality from the perspective of creating environmentally sustainable products [168-170].

Zhang et al. [171] reviewed the FEA of composite plates after the 1990s and explored different models for designing the composites. Chen et al. [113] developed hybrid fabric panels with ballistic performance where they implemented FEA to predict the different fabric layer responses against impact load. Through FEA study, they summarized that the use of shear resistant material at front layer and tensile load resistant materials as rear layer could provide improved anti-ballistic performance for laminated composites [113].

\section{Prospective research possibility and gap}

The nonlinear behavior of structural composite is still a big challenge that needs to be explored to open more diverse routes of application. The failure and crack propagations while applying the cyclic load also requires further research. In addition, the damage related to micromechanical aspect is another needed research area. Moreover, multiscale modeling of crack propagations, crack initiations, and structure failure require more work to facilitate further improvements. The state-of-the-art design of laminated composite could also bring some significant revolutions in this sector, which could facilitate more advanced usage in multifaceted applications. Currently, the development of hybrid composites from natural and synthetic fiber originated fabrics are limited and not extensively used by manufacturers. This implies that more research and innovation could also facilitate the discovery of additional routes of potential laminated composites. Manufacturing industries also need to invest more into the latest machinery and software to ensure the feasible and convenient production of advanced, high-quality laminated composites. Efficiency demonstrates a higher production rate by maintaining qualitative products with minimized unit costs [172]. Generally, every manufacturing plant contains a research and development (R\&D) unit, which could also efficiently facilitate the development of competitive and innovative products to meet market demands. Moreover, new methods of fabric-based reinforcement for high- performance cementitious materials are evolving [173]. However, the geometry of fabrics and associated yarns also plays a critical role in bonding between the reinforcements and matrix polymers like cements [174, 175]; more research to explore the most feasible routes is also required here. Moreover, fabricreinforced laminated composites could be widely used for different parts of airplanes as shown in Fig. 24.

\section{Environmental influence of fabrics-based composites}

In the field of structural applications, reinforcement of fabric-based laminates in combination with natural and synthetic fabrics has garnered considerable interest due to environmental sustainability features. Numerous natural fibers (like flax, ramie, cotton, silk, wool, hemp, sisal, and so on) are used in fabric production and are becoming potential candidates for laminated composites manufacturing. The as-produced composites could replace traditional metallic composites. Furthermore, the increased utilization of natural sources, even in hybridization with synthetic materials, also minimizes consumption pressures in glass/carbon-based materials. These phenomena are creating positive environmental contributions by minimizing carbon footprints through environmentally-friendly sustainability. Furthermore, natural fiber-based fabric production consumes less energy and utilities than synthetic material production. On the other hand, waste (like woven/nonwoven/knitted fabrics) from textile manufacturing plants could also be utilized for composites production, which would minimize the extra-pressures on the environment via a reduction in solid waste disposal. Moreover, used fabrics could be utilized again through polymeric matrix reinforcement, which may impart significant mechanical properties by having extensive potentiality in terms of sustainable products through minimizing carbon footprints. Umar et al. [177] conducted a study on waste materials from a textile industry having both types of knit and woven wastes fabricated into laminated composites. The developed composites provided significant mechanical features that are compatible with glass fiber-reinforced composites [177]. Chen et al. conducted a study on recycled silk fabrics produced from silk waste and reinforced with epoxy poly(butylene) succinate (PBS) 


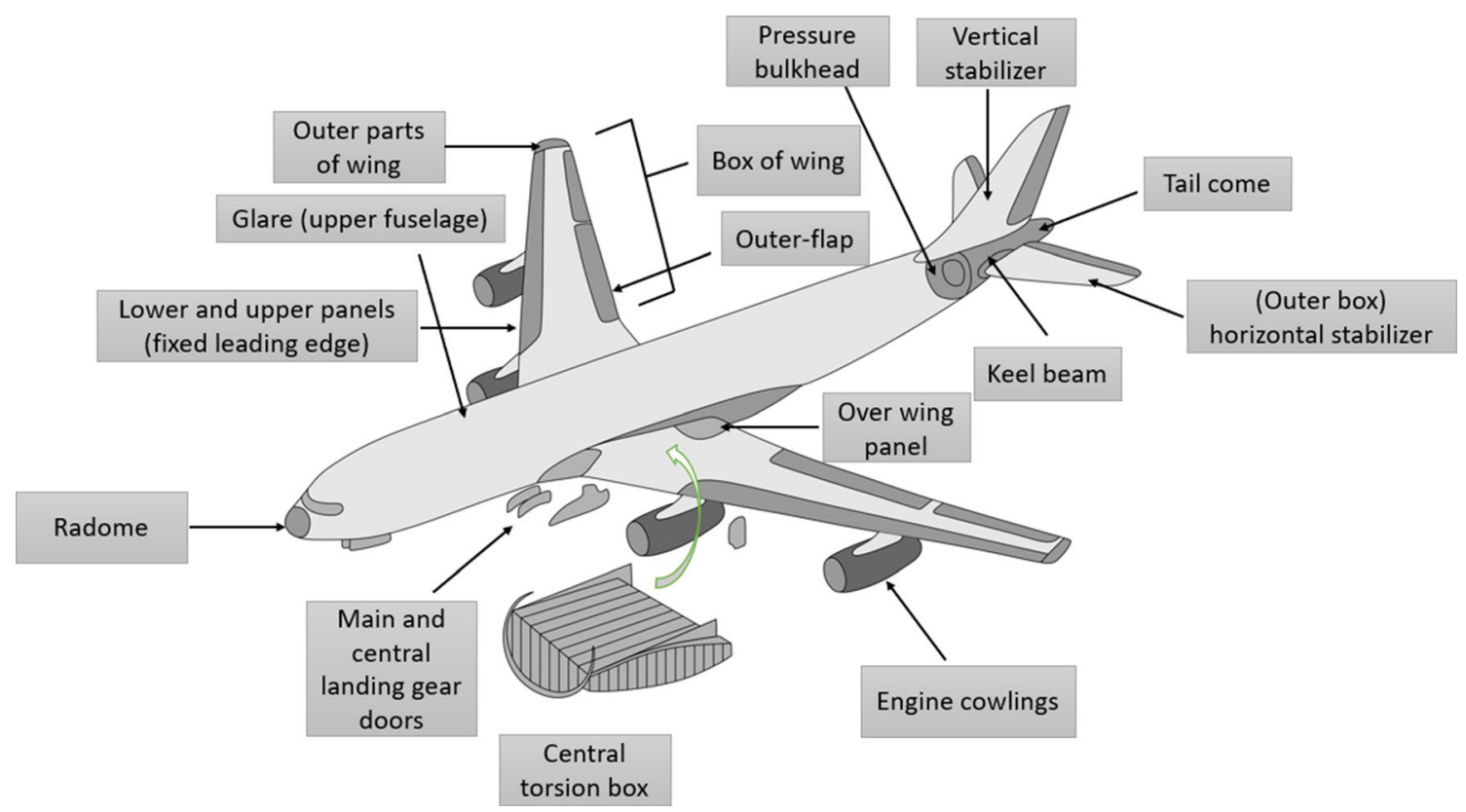

Figure 24 A schematic representation of where laminated composites could be used prominently on airplanes (A380 model of Airbus). Drawn by Péter György Horváth. Adapted with permission from Elsevier [176]. Copyright Elsevier 2011.

and found superior performance characteristics [178]. Sadrolodabaee et al. [179] conducted another study where they utilized nonwoven wastes collected from textile and garment industry residues reinforced with cement-based matrix. They revealed that all the composites provided satisfactory stress-bearing capabilities against applied load with remarkably improved and fortified properties.

\section{Potential application and marketing aspects of laminated composites}

The current global demand for composite products motivates manufacturers toward more decorative, advantageous, and diversified composite materials. Due to workforce availability and low material costs, China, Malaysia, Vietnam, Thailand, and Indonesia are currently the largest producers of laminated composites [172]. Manufactures use laminated composites extensively, although they have some limitations regarding fracture/damage of composite systems, which reduces the structural mechanical performances of the composites [180]. Due to their outstanding properties such as being light weight, anti-corrosion, superior thermo-mechanical characteristics, and overall large volume of production capabilities composites are extensively used in aircraft structural applications such as light weight aircraft, helicopters, sailplanes, light machinery parts, bridges, construction, buildings, and commuter planes [57]. Moreover, the shipbuilding sector also uses glass-reinforced laminated composites for smaller vessels like yachts and fishing boats [56]. Naval applications are also expanding from sustainable laminated composite panels [181]. Carbon-based laminations used in prominent vehicle parts are becoming more popular in automotive sector [182]. Laminated composites from glass are also being implemented in areas where safety and security issues, such as in aerospace, defense, automotive windshields, and solar cell module materials, all of which are designed from structural and architectural points of view [183-186]. Laminated composites could provide higher mechanical performances, security, and environmental sustainability as structural materials [187]. In a most recent study, Chillara et al. [188] discussed morphing technology for laminated composites. This technology could be used by soft robotics, aerospace, and automotive manufacturers as it could be shaped and tuned as per the desired performances over various ranges of operations. Defense industries are also using laminated composites [189, 190]. Furthermore, a businessfriendly environment could nourish this sector significantly throughout the world. The increasing 
demand for sustainable and cost-effective products and technology is increasing worldwide as scientific knowledge expands. Different applications of fabricreinforced composites are shown in Fig. 25. Laminated composites are becoming more appealing in the development of composites for aerospace and transportation applications.

\section{SWOT analysis of laminated composites}

SWOT analysis provides strategic planning for an organization/person to investigate strengths, weaknesses, opportunities, and threats and to obtain certain competitive benefits and ideas for businesses/operations. With this in mind, a SWOT analysis has been conducted to assess the potentiality of laminated composites (Table 2). Furthermore, through analyzing SWOT, corrective initiatives could be taken according to the necessity depending on the status of the operations/study.

\section{Conclusion}

Manufacturers produce fabric-reinforced laminated composites by combining various innovative, feasible technologies, and materials, which are recognized as advanced materials used for versatile applications. Researchers are continuously developing various fabric-based composites by combining different fibers and filaments with variable layers. Multifunctional composites with economic aspects from different fabrics also provide potential engineering solutions by reducing various processing steps and combining multiple products into a single one. High-performance fabrics are frequently reinforced with lowperformance fabrics along with suitable polymeric materials to achieve the combined positive attributions from the final laminates through minimized costs. Fabric-based composites have found new production routes and potentialities with superior performance characteristics by replacing traditional composite manufacturing methods. However, ongoing research is required to develop novel fabric-based composites to meet the increased demand of consumers in terms of cost consciousness, environment friendliness, and durability with high performances. In addition, the high production rate of fabric-based
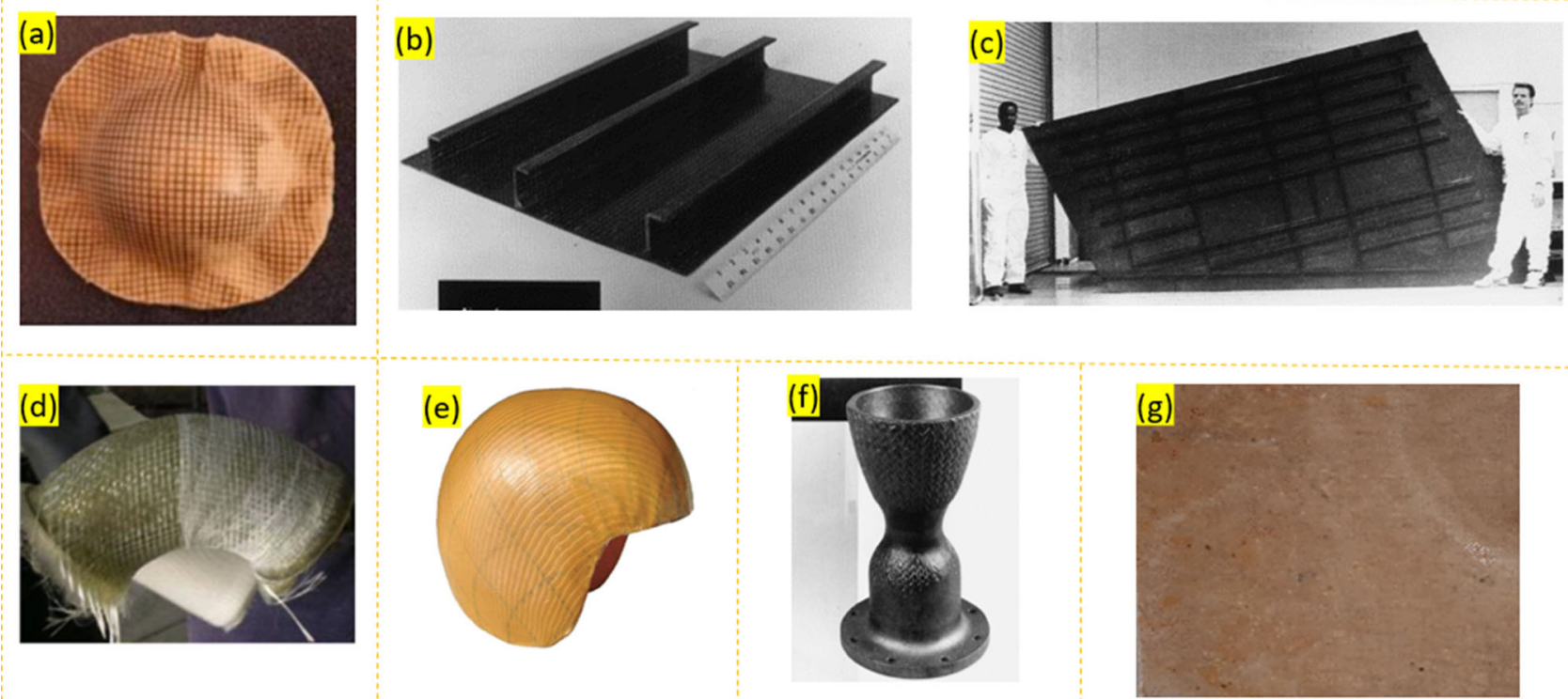

Figure 25 Various fabric-reinforced composite materials: a Bamboo woven fabric/PLA double curvature materials, $\mathbf{b}$ stiffpanel from rib structure, $\mathrm{c}$ nozzle of rocket made of braided fabric, Wing panel composite (stitched), d Elbow-fitted product, e wovenfabric molded helmet shell. Reprinted with the permission from
MDPI (under CC-BY license) (a) [191] Elsevier (b, c, d, e, and f) [192-194] and ACS (under CC-BY license) [124]. Copyright, MDPI 2016, Elsevier (b, c, d, e, and f) 2013, 2016, and1999 and ACS (g) 2021. 
Table 2 SWOT analysis of fabric-based laminated composites

\begin{tabular}{|c|c|c|}
\hline Strength & \multicolumn{2}{|c|}{ Weaknesses } \\
\hline $\begin{array}{l}\text { Laminated composites made of natural fibers like flax, hemp, } \\
\text { sisal, and ramie providing sustainable features }\end{array}$ & \multicolumn{2}{|r|}{$\begin{array}{l}\text { Could generate weaker interfacial bonding if the fibers are not treated } \\
\text { properly in composite systems }\end{array}$} \\
\hline Higher stiffness and strengths & \multicolumn{2}{|r|}{ Efficient innovations for large scale industrial production are lacking } \\
\hline Larger production volumes & \multicolumn{2}{|r|}{ Inhomogeneous characteristics varying on fabric characteristics and design } \\
\hline Bio-based laminates could be recycled & \multicolumn{2}{|r|}{$\begin{array}{l}\text { Need to combine two different production plants together like textiles for } \\
\text { fabric and composite manufacturing companies for laminated composite } \\
\text { productions together }\end{array}$} \\
\hline $\begin{array}{l}\text { Providing superior strength in terms of hybrid composites } \\
\text { made of natural and synthetic fabric reinforcements }\end{array}$ & \multicolumn{2}{|r|}{ Lack of efficient bio-based thermosetting/thermoplastic polymers } \\
\hline Newer marketing potentially is being continuously created & \multicolumn{2}{|c|}{ Lack of efficient modeling availability } \\
\hline \multicolumn{2}{|l|}{ Opportunities } & Threats \\
\hline \multicolumn{2}{|l|}{$\begin{array}{l}\text { Manufacturers and researchers are becoming more involved in } \\
\text { laminated composites production }\end{array}$} & $\begin{array}{l}\text { Nonhomogeneous quality of developed laminates, especially for } \\
\text { natural fiber-based fabric composites }\end{array}$ \\
\hline \multicolumn{2}{|l|}{ Light weight, sustainable, and economic features } & $\begin{array}{l}\text { Higher prices of synthetic fabrics like carbon, glass, aramid etc., has } \\
\text { made it difficult to ensure availability for reinforcing with bio- } \\
\text { based fabrics }\end{array}$ \\
\hline \multicolumn{2}{|l|}{$\begin{array}{l}\text { Latest technological advancements are being implemented with } \\
\text { continuous improvements from scientific methods and facilities }\end{array}$} & $\begin{array}{l}\text { Current extreme dependency on wood particle/flour-based } \\
\text { composites instead of laminations }\end{array}$ \\
\hline \multicolumn{2}{|l|}{$\begin{array}{l}\text { Natural fibers are available throughout the world, which could } \\
\text { facilitate bio-based fabric-reinforced laminated composites } \\
\text { manufacturing }\end{array}$} & $\begin{array}{l}\text { Lack of specific technological equipment for manufacturing } \\
\text { composites }\end{array}$ \\
\hline
\end{tabular}

composites would minimize costs and energy consumption. The production of energy efficient products would abate the pressure on the environment. Furthermore, the utilization of state-of-the-art technologies like numerical simulation, advanced biobased polymeric materials, processing routes, fabric treatments, nanomaterial loading, and naturally originated fabric usage to ensure sustainability could create revolutionary changes in this sector.

\section{Acknowledgements}

This work was supported by the "Stipendium Hungaricum" scholarship under the Simonyi Károly Faculty of Engineering, Wood Sciences, and Applied Arts, University of Sopron, Hungary. This article was made in the frame of "EFOP-3.6.1-16-2016-00018-improving the role of research, development, and innovation in the higher education through institutional developments assisting intelligent specialization in Sopron and Szombathely."

\section{Author contributions}

KMFH: Writing-original draft, conceptualization, methodology, data curation, investigation. PGH: Drawing, resources, conceptualization, supervision, writing-reviewing and editing. TA: conceptualization, supervision, writing - reviewing and editing.

\section{Funding}

Open access funding provided by University of Sopron.

\section{Declarations}

Conflict of interest The authors have no conflict of interest for this research.

Open Access This article is licensed under a Creative Commons Attribution 4.0 International License, which permits use, sharing, adaptation, distribution and reproduction in any medium or format, as long as you give appropriate credit to the original author(s) and the source, provide a link to the 
Creative Commons licence, and indicate if changes were made. The images or other third party material in this article are included in the article's Creative Commons licence, unless indicated otherwise in a credit line to the material. If material is not included in the article's Creative Commons licence and your intended use is not permitted by statutory regulation or exceeds the permitted use, you will need to obtain permission directly from the copyright holder. To view a copy of this licence, visit http://creativecom mons.org/licenses/by/4.0/.

\section{References}

[1] Chen X, Chen L, Zhang C, Song L, Zhang D (2016) Threedimensional needle-punching for composites: a review. Compos Part A Appl Sci 85:12-30

[2] Halpin J, Jerine K, Whitney J (1971) The laminate analogy for 2 and 3 dimensional composite materials. J Compos Mater 5(1):36-49

[3] Abounaim M, Cherif C (2012) Flat-knitted innovative three-dimensional spacer fabrics: a competitive solution for lightweight composite applications. Text Res J 82(3):288-298

[4] Bilisik K (2012) Multiaxis three-dimensional weaving for composites: a review. Text Res J 82(7):725-743

[5] Bilisik K, Karaduman NS, Bilisik NE (2016) Fiber architectures for composite applications. In: Rana S, Fangueiro $\mathrm{R}$ (eds) Fibrous and textile materials for composite applications. Springer, Singapore, pp 75-134

[6] Bini T, Ramakrishna S, Huang ZM, Lim C (2001) Structure-tensile property relationship of knitted fabric composites. Polym Compos 22(1):11-21

[7] Cheng K, Lee K, Ueng T, Mou K (2002) Electrical and impact properties of the hybrid knitted inlaid fabric reinforced polypropylene composites. Compos Part A Appl Sci Manuf 33(9):1219-1226

[8] Rajesh M, Pitchaimani J (2018) Dynamic mechanical and free vibration behavior of natural fiber braided fabric composite: comparison with conventional and knitted fabric composites. Polym Compos 39(7):2479-2489

[9] Tejyan S, Singh T, Patnaik A, Fekete G, Gangil B (2019) Physico-mechanical and erosive wear analysis of polyester fibre-based nonwoven fabric-reinforced polymer composites. J Ind Text 49(4):447-464

[10] Gholampour A, Ozbakkaloglu T (2020) A review of natural fiber composites: properties, modification and processing techniques, characterization, applications. J Mater Sci. h ttps://doi.org/10.1007/s10853-019-03990-y
[11] Hasan KMF (2015) Study on the changes of gsm (gm/m 2) of grey knitted fabric from pretreatment to finishing. Int $\mathrm{J}$ Text Sci 4(6):119-136

[12] Hasan KMF, Horváth PG, Alpár T (2020) Potential natural fiber polymeric nanobiocomposites: a review. Polymers 12(5):1-25

[13] Pervez M, Talukder M, Shafiq F, Hasan K, Taher M, Meraz M, Cai Y, Lin L (2018) Effect of heat-setting on UV protection and antibacterial properties of cotton/spandex fabric. IOP Conf Ser Mater Sci Eng. https://doi.org/10.1088/1757$899 \mathrm{X} / 284 / 1 / 012010$

[14] Hasan K, Pervez M, Talukder M, Sultana M, Mahmud S, Meraz M, Bansal V, Genyang C (2019) A novel coloration of polyester fabric through green silver nanoparticles (GAgNPs@PET). Nanomaterials 9(4):1-13

[15] Hasan KMF, Horváth PG, Horváth A, Alpár T (2021) Coloration of woven glass fabric using biosynthesized silver nanoparticles from Fraxinus excelsior tree flower. Inorg Chem Commun 126:1-7

[16] Hasan KF, Wang H, Mahmud S, Genyang C (2020) Coloration of aramid fabric via in-situ biosynthesis of silver nanoparticles with enhanced antibacterial effect. Inorg Chem Commun 119:1-8

[17] Hasan KMF, Wang H, Mahmud S, Jahid MA, Islam M, Jin W, Genyang C (2020) Colorful and antibacterial nylon fabric via in-situ biosynthesis of chitosan mediated nanosilver. J Mater Res Technol 9(6):16135-16145

[18] Sultana MZ, Mahmud S, Pervez MN, Hasan KF, Heng Q (2019) Green synthesis of glycerol monostearate-modified cationic waterborne polyurethane. Emerg Mater Res $8(2): 137-147$

[19] Zhang Y, Li Y, Ma H, Yu T (2013) Tensile and interfacial properties of unidirectional flax/glass fiber reinforced hybrid composites. Compos Sci Technol 88:172-177

[20] Zhou G, Sun Q, Li D, Meng Z, Peng Y, Zeng D, Su X (2020) Effects of fabric architectures on mechanical and damage behaviors in carbon/epoxy woven composites under multiaxial stress states. Polym Test 90:1-11

[21] Kang Y-A, Oh S-H, Park JS (2015) Properties of UHMWPE fabric reinforced epoxy composite prepared by vacuum-assisted resin transfer molding. Fibers Polym 16(6):1343-1348

[22] Prasad PR, Prakash J, Manjunath L, Reddy PV (2020) Physical and wear properties of UHMWPE fabric reinforced epoxy composites. Int $\mathrm{J}$ Automot Mech Eng 17(1):7577-7586

[23] Cheng K, Ramakrishna S, Lee K (2000) Development of conductive knitted-fabric-reinforced thermoplastic composites for electromagnetic shielding applications. J Thermoplast Compos Mater 13(5):378-399 
[24] Liu H, Falzon BG, Li S, Tan W, Liu J, Chai H, Blackman BR, Dear J (2019) Compressive failure of woven fabric reinforced thermoplastic composites with an open-hole: an experimental and numerical study. Compos Struct 213:108-117

[25] Peled A, Bentur A (2000) Geometrical characteristics and efficiency of textile fabrics for reinforcing cement composites. Cem concr Res 30(5):781-790

[26] Striewe J, Reuter C, Sauerland K-H, Tröster T (2018) Manufacturing and crashworthiness of fabric-reinforced thermoplastic composites. Thin-Walled Struct 123:501-508

[27] Yu WR, Pourboghrat F, Chung K, Zampaloni M, Kang TJ (2002) Non-orthogonal constitutive equation for woven fabric reinforced thermoplastic composites. Compos Part A Appl Sci Manuf 33(8):1095-1105

[28] Lomov S, Verpoest I (2005) Manufacturing and internal geometry of textiles. Design and manufacture of textile composites. Woodhead Publishing, Duxford, pp 1-61

[29] Ogin SL (2000) Textile-reinforced composite materials. Handbook of technical textiles. CRC Press, Boca Raton, pp 264-279

[30] Hearle JW, Grosberg P, Backer S (1969) Structural mechanics of fibers, yarns, and fabrics. Wiley-Interscience, New York

[31] Corbin A-C, Sala B, Soulat D, Ferreira M, Labanieh A-R, Placet V (2021) Development of quasi-unidirectional fabrics with hemp fiber: a competitive reinforcement for composite materials. J Compos Mater 55(4):551-564

[32] Liang Y, Wang H, Gu X (2013) In-plane shear response of unidirectional fiber reinforced and fabric reinforced carbon/ epoxy composites. Polym Test 32(3):594-601

[33] Zangenberg J, Brøndsted P, Gillespie JW Jr (2014) Fatigue damage propagation in unidirectional glass fibre reinforced composites made of a non-crimp fabric. J Compos Mater 48(22):2711-2727

[34] Feraboli P, Cleveland T, Ciccu M, Stickler P, DeOto L (2010) Defect and damage analysis of advanced discontinuous carbon/epoxy composite materials. Compos Part A Appl Sci Manuf 41(7):888-901

[35] Feraboli P, Cleveland T, Stickler P, Halpin J (2010) Stochastic laminate analogy for simulating the variability in modulus of discontinuous composite materials. Compos Part A Appl Sci 41(4):557-570

[36] Jamshaid H, Mishra R (2016) Thermomechanical characteristics of basalt hybrid and nonhybrid woven fabric-reinforced epoxy composites. Polym Compos 37(10):2982-2994

[37] Aghaei M, Shokrieh MM, Mosalmani R (2020) Effect of warp and fill-fiber volume fractions on mechanical properties of glass/epoxy woven fabric composites. J Compos Mater 54(24):3501-3513

[38] Chen J-C, Zhuang Y-F (2020) Tension and compression of sandwich composites with weft-knit fabric cores. Mod Phys Lett B 34(07n09):2040004

[39] Ramakrishna S (1997) Characterization and modeling of the tensile properties of plain weft-knit fabric-reinforced composites. Compos Sci Technol 57(1):1-22

[40] Quan Z, Wu A, Keefe M, Qin X, Yu J, Suhr J, Byun J-H, Kim B-S et al (2015) Additive manufacturing of multidirectional preforms for composites: opportunities and challenges. Mater Today 18(9):503-512

[41] Standard A (2012) Standard terminology for additive manufacturing technologies. ASTM International

[42] Tejyan S, Sharma D, Gangil B, Patnaik A, Singh T (2020) Thermo-mechanical characterization of nonwoven fabric reinforced polymer composites. Mater Today. https://doi. org/10.1016/j.matpr.2020.10.972

[43] Pan Y-J, Lou C-W, Hsieh C-T, Huang C-H, Lin Z-I, Li C-W, Lin J-H (2016) Nonwoven fabric/spacer fabric/polyurethane foam composites: physical and mechanical evaluations. Fibers Polym 17(5):789-794

[44] Yan L, Kasal B, Huang L (2016) A review of recent research on the use of cellulosic fibres, their fibre fabric reinforced cementitious, geo-polymer and polymer composites in civil engineering. Compos Part B Eng 92:94-132

[45] Haque MS (2014) Processing and characterization of waste denim fiber reinforced polymer composites. Department of materials and metallurgical engineering. Bangladesh University of Engineering and Technology, Dhaka, pp 1-77

[46] Corbin A-C, Soulat D, Ferreira M, Labanieh A-R, Gabrion X, Malecot P, Placet V (2020) Towards hemp fabrics for high-performance composites: influence of weave pattern and features. Compos Part B Eng 181:1-10

[47] School T (2021) Knitted fabrics and types: list of knitted fabrics. Available from: https://www.textileschool.com/25 1/knitted-fabrics-and-types/. Accessed 8 Feb, 2021

[48] Cuong N, Yamane H, Maekawa Z (2000) Mechanical properties of knitted fabric reinforced polypropylene composites. Adv Compos Mater 9(1):25-35

[49] Qi Y, Li J, Liu L (2014) Tensile properties of multilayerconnected biaxial weft knitted fabric reinforced composites for carbon fibers. Mater Des 54:678-685

[50] Alpyildiz T, Icten BM, Karakuzu R, Kurbak A (2009) The effect of tuck stitches on the mechanical performance of knitted fabric reinforced composites. Compos Struct 89(3):391-398

[51] Yilmaz KB, Sabuncuoglu B, Yildirim B, Silberschmidt VV (2020) A brief review on the mechanical behavior of 
nonwoven fabrics. J Eng Fibers Fabr. https://doi.org/10.11 77/1558925020970197

[52] Nonwoven Y (2021) Nonwoven fabric classification. Available from: http://www.yaolongnonwoven.com/en/tech nical/nonwoven-articles/nonwoven-types.html. Accessed 8th Feb, 2021

[53] Shi Y, Yu L, Li K, Li S, Dong Y, Zhu Y, Fu Y, Meng F (2020) Well-matched impedance of polypyrrole-loaded cotton non-woven fabric/polydimethylsiloxane composite for extraordinary microwave absorption. Compos Sci Technol 197:108246

[54] Wang J, Ma C, Chen G, Dai P (2020) Interlaminar fracture toughness and conductivity of carbon fiber/epoxy resin composite laminate modified by carbon black-loaded polypropylene non-woven fabric interleaves. Compos Struct 234:111649

[55] Ahmad MAA, Majid MA, Ridzuan M, Mazlee M, Gibson A (2018) Dynamic mechanical analysis and effects of moisture on mechanical properties of interwoven hemp/ polyethylene terephthalate (PET) hybrid composites. Construct Build Mater 179:265-276

[56] Lin H, Lee Y (1990) On the inelastic impact of composite laminated plate and shell structures. Compos struct 14(2):89-111

[57] Johnson AF, Pickett AK, Rozycki P (2001) Computational methods for predicting impact damage in composite structures. Compos Sci Technol 61(15):2183-2192

[58] Langella T, Rogani A, Navarro P, Ferrero J-F, Lopresto V, Langella A (2019) Experimental Study of the influence of a tensile preload on thin woven composite laminates under impact loading. J Mater Eng Perform 28(6):3203-3210

[59] Costa ML, de Almeida SFM, Rezende MC (2001) The influence of porosity on the interlaminar shear strength of carbon/epoxy and carbon/bismaleimide fabric laminates. Compos Sci Technol 61(14):2101-2108

[60] Corbin A-C, Soulat D, Ferreira M, Labanieh A-R, Gabrion X, Malecot P, Placet V (2020) Towards hemp fabrics for high-performance composites: influence of weave pattern and features. Compos Part B Eng 181:107582

[61] Ali A, Nasir MA, Khalid MY, Nauman S, Shaker K, Khushnood S, Altaf K, Zeeshan M et al (2019) Experimental and numerical characterization of mechanical properties of carbon/jute fabric reinforced epoxy hybrid composites. J Mech Sci Technol 33(9):4217-4226

[62] Kececi E, Asmatulu R (2017) Effects of moisture ingressions on mechanical properties of honeycomb-structured fiber composites for aerospace applications. Int J Adv Manuf Technol 88(1-4):459-470
[63] Sateesh N, Rao PS, Ravishanker D, Satyanarayana K (2015) Effect of moisture on GFRP composite materials. Mater Today 2(4-5):2902-2908

[64] Natarajan S, Annabattula RK (2019) Modeling crack propagation in variable stiffness composite laminates using the phase field method. Compos Struct 209:424-433

[65] Navarro P, Aubry J, Pascal F, Marguet S, Ferrero J-F, Dorival O (2014) Influence of the stacking sequence and crack velocity on fracture toughness of woven composite laminates in mode I. Eng Fract Mech 131:340-348

[66] Zhang Y, Xia Z, Ellyin F (2004) Evolution and influence of residual stresses/strains of fiber reinforced laminates. Compos Sci Technol 64(10-11):1613-1621

[67] Ghasemi AR, Tabatabaeian A, Asghari B (2019) Application of slitting method to characterize the effects of thermal fatigue, lay-up arrangement and MWCNTs on the residual stresses of laminated composites. Mech Mater 134:185-192

[68] Tabatabaeian A, Ghasemi AR, Asghari B (2019) Specification of non-uniform residual stresses and tensile characteristic in laminated composite materials exposed to simulated space environment. Polym Test 80:1-8

[69] Akbari S, Taheri-Behrooz F, Shokrieh M (2013) Slitting measurement of residual hoop stresses through the wallthickness of a filament wound composite ring. Exp Mech 53(9):1509-1518

[70] Özdemir H, Içten BM (2018) The mechanical performance of plain and plain derivative woven fabrics reinforced composites: tensile and impact properties. J Text Inst 109(1):133-145

[71] Kim J-K, Sham M-L (2000) Impact and delamination failure of woven-fabric composites. Compos Sci Technol 60(5):745-761

[72] Cavallaro PV, Hulton AW, Warner EA, Salama MM (2018) Cold temperature effects on consistent and architecturally hybridized woven kevlar/epoxy laminates. J Dyn Behav Mater 4(3):282-295

[73] Stegschuster G, Pingkarawat K, Wendland B, Mouritz A (2016) Experimental determination of the mode I delamination fracture and fatigue properties of thin $3 \mathrm{D}$ woven composites. Compos Part A Appl Sci Manuf 84:308-315

[74] Triki E, Zouari B, Dammak F (2016) Dependence of the interlaminar fracture toughness of E-glass/polyester woven fabric composites laminates on ply orientation. Engin Fract Mech 159:63-78

[75] Dai S, Cunningham P, Marshall S, Silva C (2015) Influence of fibre architecture on the tensile, compressive and flexural behaviour of 3D woven composites. Compos Part A Appl Sci Manuf 69:195-207 
[76] Kang H, Shan Z, Zang Y, Liu F (2016) Progressive damage analysis and strength properties of fiber-bar composites reinforced by three-dimensional weaving under uniaxial tension. Compos Struct 141:264-281

[77] Zhou Y, Lu Z, Yang Z (2013) Progressive damage analysis and strength prediction of 2D plain weave composites. Compos Part B Eng 47:220-229

[78] Fang G, Liang J (2011) A review of numerical modeling of three-dimensional braided textile composites. J Compos Mater 45(23):2415-2436

[79] Vieille B, Casado VM, Bouvet C (2013) About the impact behavior of woven-ply carbon fiber-reinforced thermoplastic-and thermosetting-composites: a comparative study. Compos Struct 101:9-21

[80] Anuar NIS, Zakaria S, Gan S, Chia CH, Wang C, Harun J (2019) Comparison of the morphological and mechanical properties of oil Palm EFB fibres and kenaf fibres in nonwoven reinforced composites. Ind Crops Prod 127:55-65

[81] Habibi M, Laperrière L, Hassanabadi HM (2018) Influence of low-velocity impact on residual tensile properties of nonwoven flax/epoxy composite. Compos Struct 186:175-182

[82] Hasani H, Hassanzadeh S, Abghary MJ, Omrani E (2017) Biaxial weft-knitted fabrics as composite reinforcements: a review. J Ind Text 46(7):1439-1473

[83] Hessami R, Alamdar Yazdi A, Mazidi A (2019) The effect of loop density on the tensile behavior of biaxial weft knitted composites using both experimental tests and numerical method. J Ind Text. https://doi.org/10.1177/ 1528083719868177

[84] Hasan KMF, Péter GH, Tibor LA (2021) Design and fabrication technology in biocomposite manufacturing. Toward the value-added biocomposites: technology, innovation and opportunity. CRC Press, Boca Raton

[85] Ishak KA, Velayutham TS, Annuar MSM, Sirajudeen AAO (2021) Structure-property interpretation of biological polyhydroxyalkanoates with different monomeric composition: dielectric spectroscopy investigation. Int J Biol Macromol 169:311-320

[86] Mahmud S, Hasan KF, Jahid MA, Mohiuddin K, Zhang R, Zhu J (2021) Comprehensive review on plant fiber-reinforced polymeric biocomposites. J Mater Sci. https://doi. org/10.1007/s10853-021-05774-9

[87] Rajeswari A, Christy EJS, Pius A (2021) Biopolymer blends and composites: processing technologies and their properties for industrial applications. In: Sabu T, Sreeraj G, Augustine A (eds) Biopolymers and their industrial applications. Elsevier, Duxford, pp 105-147

[88] Tibor LA, Péter GH Hasan KMF (2021) Introduction to biomass and biocomposites. In: Toward the value-added biocomposites: technology, innovation and opportunity. CRC Press, Boca Raton

[89] Frank A, Messiha M, Koch T, Poduška J, Hutař P, Arbeiter F, Pinter G (2021) Correlation of the cyclic cracked round bar test and hydrostatic pressure test for unplasticized polyvinylchloride. Polym Test 95:1-7

[90] Hasan KF, Horváth PG, Kóczán Z, Alpár T (2021) Thermomechanical properties of pretreated coir fiber and fibrous chips reinforced multilayered composites. Sci Rep 11:3618

[91] Hasan KF, Horváth PG, Miklos B, Alpár T (2021) A stateof-the-art review on coir fiber-reinforced biocomposites. RSC Adv 11:10548-10571

[92] Hasan KF, Horváth PTGR, Baş S, Alpár T (2021) Industrial flame-retardants for polyurethanes. In: Gupta R (ed) Materials and chemistry of flame-retardant polyurethanes. American Chemical Society, Washington

[93] Liu H, Zhu L-L, He Y, Cheng B-W (2017) A novel method for fabricating elastic conductive polyurethane filaments by in-situ reduction of polydopamine and electroless silver plating. Mater Des 113:254-263

[94] Miller J, Liaw P, Landes J (2001) Influence of fiber coating thickness on fracture behavior of continuous woven Nicalon ${ }^{\circledR}$ fabric-reinforced silicon-carbide matrix ceramic composites. Mater Sci 317(1-2):49-58

[95] Rajaei M, Wang D-Y, Bhattacharyya D (2017) Combined effects of ammonium polyphosphate and talc on the fire and mechanical properties of epoxy/glass fabric composites. Compos Part B Eng 113:381-390

[96] Hammiche D, Boukerrou A, Guermazi N, Arrakhiz FE (2021) Effects of types of PVC-g-MA on wettability and dynamical behavior of polyvinyl chloride/Alfa composites. Mater Today 36:10-15

[97] Choudhry RS, Hassan SF, Li S, Day R (2015) Damage in single lap joints of woven fabric reinforced polymeric composites subjected to transverse impact loading. Int $\mathbf{J}$ Imp Eng 80:76-93

[98] Gou J-J, Gong C-L, Gu L-X, Li S, Tao W-Q (2018) The unit cell method in predictions of thermal expansion properties of textile reinforced composites. Compos Struct 195:99-117

[99] Gou J-J, Ren X-J, Fang W-Z, Li S, Tao W-Q (2018) Two small unit cell models for prediction of thermal properties of 8-harness satin woven pierced composites. Compos B Eng 135:218-231

[100] Li H, Li S, Wang Y (2011) Prediction of effective thermal conductivities of woven fabric composites using unit cells at multiple length scales. J Mater Res 26(3):384

[101] Li S, Zhou C, Yu H, Li L (2011) Formulation of a unit cell of a reduced size for plain weave textile composites. Comput Mater Sci 50(5):1770-1780 
[102] Lomov SV, Huysmans G, Luo Y, Parnas R, Prodromou A, Verpoest I, Phelan F (2001) Textile composites: modelling strategies. Compos Part A Appl Sci Manuf 32(10):1379-1394

[103] Lomov SV, Ivanov DS, Verpoest I, Zako M, Kurashiki T, Nakai H, Hirosawa S (2007) Meso-FE modelling of textile composites: road map, data flow and algorithms. Compos Sci Technol 67(9):1870-1891

[104] Tan P, Tong L, Steven G (1997) Modelling for predicting the mechanical properties of textile composites: a review. Compos Part A Appl Sci Manuf 28(11):903-922

[105] Thompson AJ, McFarlane JR, Belnoue JP-H, Hallett SR (2020) Numerical modelling of compaction induced defects in thick 2D textile composites. Mater Des 196:1-10

[106] Varas D, Artero-Guerrero J, Pernas-Sánchez J, LópezPuente J (2013) Analysis of high velocity impacts of steel cylinders on thin carbon/epoxy woven laminates. Compos Struct 95:623-629

[107] Xu M, Sitnikova E, Li S (2020) Unification and parameterisation of $2 \mathrm{D}$ and $3 \mathrm{D}$ weaves and the formulation of a unit cell for composites made of such preforms. Compos Part A Appl Sci Manuf 133:1-14

[108] Yu J, Zhou C, Li S (2020) Experimental and numerical research on the mode I delamination of looped fabric reinforced laminate. Compos B Eng 182:107566

[109] Green S, Long A, El Said B, Hallett S (2014) Numerical modelling of $3 \mathrm{D}$ woven preform deformations. Compos Struct 108:747-756

[110] Ghazimoradi M, Carvelli V, Naouar N, Boisse P (2020) Experimental measurements and numerical modelling of the mechanical behaviour of a glass plain weave composite reinforcement. J Reinf Plast Compos 39(1-2):45-59

[111] Wang C, Roy A, Chen Z, Silberschmidt VV (2017) Braided textile composites for sports protection: energy absorption and delamination in impact modelling. Mater Des 136:258-269

[112] De Carvalho N, Pinho S, Robinson P (2012) Numerical modelling of woven composites: biaxial loading. Compos Part A Appl Sci Manuf 43(8):1326-1337

[113] Chen X, Zhou Y, Wells G (2014) Numerical and experimental investigations into ballistic performance of hybrid fabric panels. Compos Part B Eng 58:35-42

[114] Gou J-J, Gong C-L, Gu L-X, Li S, Tao W-Q (2017) Unit cells of composites with symmetric structures for the study of effective thermal properties. Appl Therm Eng 126:602-619

[115] Li H, Kandare E, Li S, Wang Y, Kandola BK, Myler P, Horrocks A (2012) Micromechanical finite element analyses of fire-retarded woven fabric composites at elevated temperatures using unit cells at multiple length scales. Comput Mater Sci 55:23-33

[116] Li S, L a Jeanmeure, and Q Pan, (2015) A composite material characterisation tool: UnitCells. J Eng Math 95(1):279-293

[117] Li S, Sitnikova E (2018) An excursion into representative volume elements and unit cells. Comprehensive composite materials II. Elsevier, Amsterdam, pp 451-489

[118] Li S, Warrior N, Zou Z, Almaskari F (2011) A unit cell for FE analysis of materials with the microstructure of a staggered pattern. Compos Part A Appl Sci Manuf 42(7):801-811

[119] Li S, Zou Z (2011) The use of central reflection in the formulation of unit cells for micromechanical FEA. Mech Mater 43(12):824-834

[120] Fang W-Z, Chen L, Gou J-J, Tao W-Q (2016) Predictions of effective thermal conductivities for three-dimensional four-directional braided composites using the lattice Boltzmann method. Int J Heat Mass Transf 92:120-130

[121] Gou J-J, Fang W-Z, Dai Y-J, Li S, Tao W-Q (2017) Multisize unit cells to predict effective thermal conductivities of 3D four-directional braided composites. Compos Struct 163:152-167

[122] Gou J-J, Zhang H, Dai Y-J, Li S, Tao W-Q (2015) Numerical prediction of effective thermal conductivities of 3D four-directional braided composites. Compos Struct 125:499-508

[123] Hasan KF, Horváth PG, Markó G, Alpár T (2021) Thermomechanical characteristics of flax-woven-fabric-reinforced poly (lactic acid) and polypropylene biocomposites. Green Mater 40(XXXX):1-10

[124] Hasan KF, Horváth PG, Alpár T (2021) Thermomechanical behavior of methylene diphenyl diisocyanate-bonded flax/glass woven fabric reinforced laminated composites. ACS Omega 6(9):6124-6133

[125] Monteiro SN, de Assis FS, Ferreira CL, Simonassi NT, Weber RP, Oliveira MS, Colorado HA, Pereira AC (2018) Fique fabric: a promising reinforcement for polymer composites. Polymers 10(3):246

[126] Rouf K, Denton NL, French RM (2017) Effect of fabric weaves on the dynamic response of two-dimensional woven fabric composites. Jof Mater Sci 52(17):10581-10591

[127] Farooq U, Myler P (2016) Finite element simulation of damage and failure predictions of relatively thick carbon fibre-reinforced laminated composite panels subjected to flat and round noses low velocity drop-weight impact. Thin-Wall Struct 104:82-105

[128] Arpitha G, Sanjay M, Senthamaraikannan P, Barile C, Yogesha B (2017) Hybridization effect of sisal/glass/ 
epoxy/filler based woven fabric reinforced composites. Exp Tech 41(6):577-584

[129] Aruchamy K, Subramani SP, Palaniappan SK, Sethuraman B, Kaliyannan GV (2020) Study on mechanical characteristics of woven cotton/bamboo hybrid reinforced composite laminates. J Mater Res Technol 9(1):718-726

[130] Kumar SV, Kumar KS, Jailani HS, Rajamurugan G (2020) Mechanical, DMA and sound acoustic behaviour of flax woven fabric reinforced epoxy composites. Mater Res Exp 7(8):085302

[131] Khalid MY, Nasir MA, Ali A, Al Rashid A, Khan MR (2020) Experimental and numerical characterization of tensile property of jute/carbon fabric reinforced epoxy hybrid composites. SN Appl Sci 2(4):1-10

[132] Misnon M, Islam M, Epaarachchi J, Chen H, Goda K, Khan M (2018) Flammability characteristics of chemical treated woven hemp fabric reinforced vinyl ester composites. Sci Technol Mater 30(3):174-188

[133] Aisyah H, Paridah M, Khalina A, Sapuan S, Wahab M, Berkalp O, Lee C, Lee S (2018) Effects of fabric counts and weave designs on the properties of laminated woven kenaf/carbon fibre reinforced epoxy hybrid composites. Polymers 10(12):1320

[134] Chen X, Zhang N, Gu S, Li J, Ren J (2014) Preparation and properties of ramie fabric-reinforced thermoset poly lactic acid composites. J Reinf Plast Compos 33(10):953-963

[135] Ma P, Hu H, Zhu L, Sun B, Gu B (2011) Tensile behaviors of co-woven-knitted fabric reinforced composites under various strain rates. J Compos Mater 45(24):2495-2506

[136] Tiber B, Balcıŏglu HE (2019) Flexural and fracture behavior of natural fiber knitted fabric reinforced composites. Polym Compos 40(1):217-228

[137] Kakati N, Assanvo EF, Kalita D (2019) Synthesis and performance evaluation of unsaturated polyester blends of resins and its application on non-woven/fabric jute fibers reinforced composites. J Polym Environ 27(11):2540-2548

[138] Ariawan D, Salim M, Taib RM, Thirmizir MA, Ishak ZM (2018) Interfacial characterisation and mechanical properties of heat treated non-woven kenaf fibre and its reinforced composites. Compos Interfaces 25(2):187-203

[139] Pantaloni D, Shah D, Baley C, Bourmaud A (2020) Monitoring of mechanical performances of flax non-woven biocomposites during a home compost degradation. Polym Degrad Stab 177:1-12

[140] Hasan KMF, Péter GH, Gábor M, Tibor A (2021) Thermomechanical characteristics of flax woven fabric reinforced PLA and PP biocomposites. Green Mater. https://doi.org/ 10.1680/jgrma.20.00052
[141] İlçe AC, Budakçı M, Özdemir S, Akkuş M (2015) Analysis of usability in furniture production of wood plastic laminated board. BioResources 10(3):4300-4314

[142] Jawaid M, Thariq M, Saba N (2018) Mechanical and physical testing of biocomposites, fibre-reinforced composites and hybrid composites. Woodhead Publishing, Duxford. pp-1-441

[143] Naresh K, Shankar K, Rao B, Velmurugan R (2016) Effect of high strain rate on glass/carbon/hybrid fiber reinforced epoxy laminated composites. Compos Part B Eng 100:125-135

[144] de Paiva JMF, Mayer S, Rezende MC (2006) Comparison of tensile strength of different carbon fabric reinforced epoxy composites. Mater Res 9(1):83-90

[145] Hasan KMF, Péter György H, Tibor A (2020) Thermomechanical behavior of MDI bonded flax/glass woven fabric reinforced laminated composites. ACS Omega. http s://doi.org/10.1021/acsomega.0c04798

[146] Zhang J, Chaisombat K, He S, Wang CHJ (2012) Hybrid composite laminates reinforced with glass/carbon woven fabrics for lightweight load bearing structures. Mater Des 36:75-80

[147] Intertek. Flexural Properties Testing. [cited 2021 26th February]; Available from: https://www.intertek.com/poly mers/testing/flexural-properties/\#: :text=Flexural\%20Pro perties $\% 20$ Testing\%20Scope,a\%20material's\%20stiffnes s\%20when\%20flexed

[148] Jayaraman K (2003) Manufacturing sisal-polypropylene composites with minimum fibre degradation. Compos Sci Technol 63(3-4):367-374

[149] Reis P, Ferreira J, Antunes F, Costa J (2007) Flexural behaviour of hybrid laminated composites. Compos Part A Appl Sci Manuf 38(6):1612-1620

[150] Hasan KF, Horváth PG, Alpár T (2021) Development of lignocellulosic fiber reinforced cement composite panels using semi-dry technology. Cellulose 28:3631-45

[151] Bandaru AK, Patel S, Sachan Y, Alagirusamy R, Bhatnagar N, Ahmad S (2016) Low velocity impact response of 3D angle-interlock Kevlar/basalt reinforced polypropylene composites. Mater Des 105:323-332

[152] Argüello-Bastos J, González-Estrada O, Ruiz-Florián C, Pertuz-ComasNiño AEV (2018) Study of mechanical properties under compression failure in reinforced composite materials produced by additive manufacturing. J Phys Conf Ser 1126(1):1-7

[153] Arhant M, Le Gac P-Y, Le Gall M, Burtin C, Briançon C, Davies P (2016) Effect of sea water and humidity on the tensile and compressive properties of carbon-polyamide 6 laminates. Compos Part A Appl Sci Manuf 91:250-261 
[154] Cocchi A, Montagnier O, Hochard C (2021) Study of hourglass-shaped specimens for the analysis of compression behaviour in fibre direction of FRP composites using compression and four-point bending tests. Compos Part A Appl Sci Manuf 144:1-12

[155] Dehkordi MT, Nosraty H, Shokrieh MM, Minak G, Ghelli D (2013) The influence of hybridization on impact damage behavior and residual compression strength of intraply basalt/nylon hybrid composites. Mater Des 43:283-290

[156] Kannan TG, Wu CM, Cheng KB, Wang CY (2013) Effect of reinforcement on the mechanical and thermal properties of flax/polypropylene interwoven fabric composites. J Ind Text 42(4):417-433

[157] Yan L, Chouw N, Jayaraman K (2015) Effect of UV and water spraying on the mechanical properties of flax fabric reinforced polymer composites used for civil engineering applications. Mater Des 71:17-25

[158] Tserki V, Matzinos P, Zafeiropoulos N, Panayiotou C (2006) Development of biodegradable composites with treated and compatibilized lignocellulosic fibers. J Appl Polym Sci 100(6):4703-4710

[159] Yan L, Chouw N, Jayaraman K (2014) Flax fibre and its composites: a review. Compos Part B Eng 56:296-317

[160] Dhakal HN, Sarasini F, Santulli C, Tirillò J, Zhang Z, Arumugam V (2015) Effect of basalt fibre hybridisation on post-impact mechanical behaviour of hemp fibre reinforced composites. Compos Part A Appl Sci Manuf 75:54-67

[161] Jarukumjorn K, Suppakarn N (2009) Effect of glass fiber hybridization on properties of sisal fiber-polypropylene composites. Compos Part B Eng 40(7):623-627

[162] Hasan KMF, Horváth PG, Alpár T (2020) Potential natural fiber polymeric nanobiocomposites: a review. Polymers 12(5):1-25

[163] Sanjay M, Madhu P, Jawaid M, Senthamaraikannan P, Senthil S, Pradeep S (2018) Characterization and properties of natural fiber polymer composites: a comprehensive review. J Clean Prod 172:566-581

[164] Cerbu C, Boti[Error hu0219] M (2017) Numerical modeling of the flax/glass/epoxy hybrid composite materials in bending. Proc Eng 181:308-315

[165] Rana R, Rana S, Purohit R (2017) Characterization of properties of epoxy sisal/glass fiber reinforced hybrid composite. Mater Today 4(4):5445-5451

[166] Kumar CN, Prabhakar M, Song J-i (2019) Effect of interface in hybrid reinforcement of flax/glass on mechanical properties of vinyl ester composites. Polym Test 73:404-411

[167] Abrate S (1991) Matrix cracking in laminated composites: a review. Compos Eng 1(6):337-353
[168] Han Y, Zhang X, Wu X, Lu C (2015) Flame retardant, heat insulating cellulose aerogels from waste cotton fabrics by in situ formation of magnesium hydroxide nanoparticles in cellulose gel nanostructures. ACS Sustain Chem Eng 3(8):1853-1859

[169] Masood Z, Ahmad S, Umair M, Shaker K, Nawab Y, Karahan M (2018) Mechanical behaviour of hybrid composites developed from textile waste. Fibres Text East Eur 26(1):46-52

[170] Temmink R, Baghaei B, Skrifvars M (2018) Development of biocomposites from denim waste and thermoset bioresins for structural applications. Compos Part A Appl Sci Manuf 106:59-69

[171] Zhang Y, Yang C (2009) Recent developments in finite element analysis for laminated composite plates. Compos Struct 88(1):147-157

[172] Suhaily S, Jawaid M, Khalil HA, Mohamed AR, Ibrahim F (2012) A review of oil palm biocomposites for furniture design and applications: potential and challenges. BioResources 7(3):4400-4423

[173] Peled A, Bentur A (2000) Geometrical characteristics and efficiency of textile fabrics for reinforcing cement composites. Cem Concr Res 30(5):781-790

[174] Peled A, Bentur A (1998) Reinforcement of cementitious matrices by warp knitted fabrics. Mater Struct 31(8):543-550

[175] Peled A, Bentur A, Yankelevsky D (1998) Effects of woven fabric geometry on the bonding performance of cementitious composites: mechanical performance. $\mathrm{Adv} \mathrm{Cem}$ Based Mater 7(1):20-27

[176] Sinmazçelik T, Avcu E, Bora MÖ, Çoban O (2011) A review: fibre metal laminates, background, bonding types and applied test methods. Mater Des 32(7):3671-3685

[177] Umar M, Shaker K, Ahmad S, Nawab Y, Umair M, Maqsood M (2017) Investigating the mechanical behavior of composites made from textile industry waste. J Text Inst 108(5):835-839

[178] Chen S, Cheng L, Huang H, Zou F, Zhao H-P (2017) Fabrication and properties of poly (butylene succinate) biocomposites reinforced by waste silkworm silk fabric. Compos Part A Appl Sci Manuf 95:125-131

[179] Sadrolodabaee P, Claramunt J, Ardanuy M, de la Fuente A (2021) Characterization of a textile waste nonwoven fabric reinforced cement composite for non-structural building components. Constr Build Mater 276:1-17

[180] Abrate S (1994) Impact on laminated composites: recent advances. Appl Mech Rev 47(11):517-544

[181] Hassoon OH, Tarfaoui M, El Moumen A (2017) Progressive damage modeling in laminate composites under 
slamming impact water for naval applications. Compos Struct 167:178-190

[182] Adam H (1997) Carbon fibre in automotive applications. Mater Des 18(4-6):349-355

[183] Bolton NP, Smith N (1991) Laminated safety glass. Google Patents, United States

[184] Savineau G, Serruys F (2001) Durability and postbreakage behaviour of laminated safety glass. In Glass Processing Days 2001 conference proceedings book. pp 328-330

[185] Stephinson WP (1994) Bullet resistant glass. Google Patents, United States

[186] Teotia M, Soni R (2018) Applications of finite element modelling in failure analysis of laminated glass composites: a review. Eng Fail Anal 94:412-437

[187] Barile C, Casavola C, De Cillis F (2019) Mechanical comparison of new composite materials for aerospace applications. Compos Part B Eng 162:122-128

[188] Chillara V, Dapino M (2020) Review of morphing laminated composites. Appl Mech Rev 72(1):1-16

[189] Guo Y, Dong Q, Chen J, Yao X, Yi X, Jia Y (2017) Comparison between temperature and pyrolysis dependent models to evaluate the lightning strike damage of carbon fiber composite laminates. Compos Part A Appl Sci Manuf 97:10-18
[190] Liu D, Tang Y, Cong W (2012) A review of mechanical drilling for composite laminates. Compos Struct 94(4):1265-1279

[191] Nurul MR, Jayaraman K, Bhattacharyya D (2016) Formability analysis of bamboo fabric reinforced poly (Lactic) acid composites. Materials 9(7):1-19

[192] Chen X, Taylor L, Tsai L-J (2016) Three-dimensional fabric structures: part 1-an overview on fabrication of three-dimensional woven textile preforms for composites. In Handbook of technical textiles. CRC Press, Boca Raton. pp 285-304

[193] La Rosa A, Cozzo G, Latteri A, Recca A, Björklund A, Parrinello E, Cicala G (2013) Life cycle assessment of a novel hybrid glass-hemp/thermoset composite. J Clean Prod 44:69-76

[194] Mouritz AP, Bannister MK, Falzon P, Leong KJ (1999) Review of applications for advanced three-dimensional fibre textile composites. Compos Part A Appl Sci Manuf 30(12):1445-1461

Publisher's Note Springer Nature remains neutral with regard to jurisdictional claims in published maps and institutional affiliations. 